\title{
VENEZUELA: SALIDAS CONSTITUCIONALES A LA CRISIS INSTITUCIONAL*
}

\author{
MARÍA LAURA EBERHARDT ${ }^{* *}$ \\ MARIO DANIEL SERRAFERO***
}

\begin{abstract}
RESUMEN: La crisis económica, política y social de Venezuela se profundizó bajo la presidencia de Nicolás Maduro en 2016. Este trabajo analiza los diversos caminos que la Constitución y el sistema normativo venezolano ofrecen para solucionar las crisis de gobernabilidad cuando el principal problema es la legitimidad del Presidente. Las causas reconocidas de ausencia absoluta del Presidente son, entre otras, la renuncia, la destitución, la inhabilidad física o mental, el abandono del cargo, la revocatoria de mandato. Entre las opciones disponibles, la que mayor lugar y consideración ocupa en este caso es la revocatoria de mandato, pues fue el camino más factible que vio la oposición para remover al mandatario. No obstante, se interpusieron numerosos obstáculos para hacerla fracasar. El presente trabajo constituye un estudio de las herramientas y mecanismos que otorga la Constitución venezolana para superar las crisis presidenciales y analiza las acciones que los diversos actores políticos emprendieron ante la coyuntura de 2016.
\end{abstract}

PalabRas ChaVE: Venezuela - Crisis Institucional - Mecanismos Constitucionales - Revocatoria de Mandato - Legitimidad Presidencial

\footnotetext{
* $\quad$ Fecha de recepción: 4 de abril de 2017.

Fecha de aceptación: 11 de septiembre de 2017.

** Diploma de Posdoctorado (Facultad de Derecho, Universidad de Buenos Aires), Doctora en Ciencia Política (Universidad Nacional de San Martín), Magíster en Ciencia Política y Sociología (FLACSO), Licenciada en Ciencia Política (Universidad de Buenos Aires), Investigadora del CONICET, Profesora de la Universidad Nacional Arturo Jauretche y de la Universidad de Buenos Aires, Codirectora de Proyecto de investigación UBACyT. Correo electrónico: laura_rafaela@yahoo.com.ar

*** Doctor en Derecho (Universidad de Buenos Aires), Doctor en Ciencia Política y Sociología (Universidad Complutense de Madrid-Instituto Universitario Ortega y Gasset), Diploma de Especialización en Derecho Constitucional y Ciencia Política (Centro de Estudios Políticos y Constitucionales), Diploma de especialización en Sociología del Derecho (Universidad de Buenos aires), Diploma de Especialización en Altos Estudios Internacionales (Sociedad de Estudios Internacionales), Investigador Principal del CONICET, Profesor Titular de la Universidad de Buenos Aires, Miembro de Número de la Academia de Ciencias Morales y Políticas. Correo electrónico: mserrafero@gmail.com
} 


\title{
VENEZUELA: CONSTITUTIONAL CHOICES TO THE INSTITUTIONAL CRISIS
}

\begin{abstract}
The economic, political and social crisis in Venezuela has deepened under the presidency of Nicolás Maduro in 2016. This paper analyzes the different ways that the Venezuelan Constitution and the Venezuelan normative system offer to solve the crisis of governability when the main problem is the president's legitimacy. The recognized causes of the president's absolute absence are, among others, resignation, dismissal, physical or mental inability, abandonment of office, recall. Among the available options, the most important one in this case is the recall, as it was the most feasible way that the opposition found to remove the president. However, many obstacles were put in place to make it fail. The present work constitutes a study of the tools and mechanisms that the Venezuelan Constitution grants to overcome the presidential crises and analyzes the actions that the diverse political actors undertook in facing the conjuncture of 2016.
\end{abstract}

KEY WORDS: Venezuela - Institutional Crisis - Constitutional Mechanisms - Recall - Presidential Legitimacy

Sumario: Introducción - 1) La crisis y los mecanismos institucionales - 2) La Constitución de Venezuela: caminos para poner fin a un gobierno 2.1) Muerte - 2.2) Renuncia - 2.3) Abandono del cargo - 2.4) Incapacidad física o mental - 2.5) Destitución - 2.6) Asamblea Nacional Constituyente - 2.7) Enmienda constitucional - 2.8) Revocatoria de mandato - 3) La crisis venezolana de 2016. Diversas vias de salida anticipada del Presidente Nicolás Maduro. La revocatoria presidencial - Concluyendo: las opciones de la salida institucional - Bibliografía citada - Jurisprudencia citada.

\section{INTRODUCCIÓN}

En este trabajo se analiza la crisis institucional que atravesó Venezuela, especialmente en 2016, en el marco de un profundo deterioro económico y social. La política enfrentó a la sociedad venezolana dividiéndola entre chavistas y antichavistas. La muerte de Hugo Chávez, en 2013, ocasionó el llamado a nuevas elecciones que dieron el triunfo a su sucesor, designado por el propio Chávez: Nicolás Maduro. 
Maduro asumió el gobierno en 2013 y su período presidencial debiera culminar en 2019. Durante sus años de gestión la situación política, económica y social se fue degradando cada vez más y, en las elecciones legislativas de 2015, la oposición ganó la mayoría de las bancas de la Asamblea Nacional. Pero lejos de reconducirse el proceso político, el Poder Ejecutivo y el Poder Judicial fueron vaciando las facultades del Legislativo. La oposición ya se había planteado desplazar o remover al presidente Maduro y fue así que se barajaron las distintas vías o posibilidades que ofrece la Constitución y la legislación venezolana para su salida anticipada.

Este trabajo analiza los distintos caminos que la Constitución y el sistema normativo venezolano ofrece para solucionar las crisis de gobernabilidad cuando el principal problema es la legitimidad del Presidente. Entre las opciones disponibles, la que mayor lugar y consideración ocupa en este artículo es uno de los mecanismos de democracia directa incorporados (junto con el referendo, la consulta popular y otros) en la Constitución de 1999: la revocatoria de mandato, que resultó el camino más claro que vio la oposición para remover al mandatario. Cabe aclarar que por democracia directa se entiende a las diversas formas de participación política que se realizan a través del ejercicio del voto directo y universal. Su objetivo principal es involucrar al conjunto de la ciudadanía en el proceso de toma de decisiones sobre cuestiones públicas (actos o normas), y no el de elegir a los miembros de los poderes Legislativo o Ejecutivo $^{1}$. El artículo $70^{\circ}$ de la Constitución venezolana de 1999 reconoce como medios de participación y protagonismo del pueblo en ejercicio de su soberanía, en lo político: la elección de cargos públicos, el referendo, la consulta popular, la revocación del mandato, las iniciativas legislativa, constitucional y constituyente, el cabildo abierto y la asamblea de ciudadanos y ciudadanas cuyas decisiones serán de carácter vinculante, entre otros; y en lo social y económico: las instancias de atención ciudadana, la autogestión, la cogestión, las cooperativas en todas sus formas incluyendo las de carácter financiero, las cajas de ahorro, la empresa comunitaria y demás formas asociativas guiadas por los valores de la mutua cooperación y la solidaridad.

No obstante, como se muestra aquí, fueron numerosos los obstáculos que se interpusieron para que esta alternativa de revocatoria no prosperara. Respecto de la revocatoria presidencial, cabe señalar que Venezuela es uno de los tres países que poseen este mecanismo en América Latina (los otros son Bolivia y Ecuador). Dicho instrumento ya se había utilizado en

Aragón Reyes, Manuel y López González, José Luis (2000) "Plebiscito". En Diccionario electoral (Tomo II). San José: Instituto Interamericano de Derechos Humanos, pp. 981. 
ese país contra el presidente Chávez en 2004, aunque en esa ocasión la oposición perdió el referéndum y el Presidente continuó en el cargo.

El artículo comienza con una breve referencia sobre las perspectivas teóricas que ha merecido el tratamiento de las crisis institucionales y las interrupciones presidenciales en América Latina. Luego se analizan las distintas opciones que la Constitución venezolana señala en el artículo $233^{\circ}$ como ausencia absoluta del Presidente y que son: la renuncia, la destitución, la inhabilidad física o mental y la revocatoria del mandato. Asimismos se agrega la consideración de otras alternativas como la reforma y la enmienda constitucional. En el punto siguiente se refiere el proceso político dentro del cual la oposición intentó poner en práctica las distintas alternativas, siendo el referéndum revocatorio el que concitó las mayores energías y esfuerzos. Por último, se reflexiona acerca de los motivos por los cuales, hasta el momento de escribir este trabajo, ninguno de los caminos prescritos por la Constitución fue útil para reencauzar la crisis institucional venezolana, haciendo especial hincapié en las limitaciones que la revocatoria presidencial puede enfrentar cuando no cuenta con el favor del Presidente en cuestión.

\section{1) LAS CRISIS Y LOS MECANISMOS INSTITUCIONALES}

La situación venezolana y el intento de desplazamiento del presidente Maduro se inscriben dentro del marco teórico de las crisis institucionales que pueden culminar o bien con el reequilibramiento del sistema ${ }^{2}$ o bien con un cambio que conlleve la caída del Presidente.

Décadas atrás Juan Linz ${ }^{3}$ planteaba que el régimen presidencial adolecía de una extrema rigidez. Los problemas de legitimidad presidencial culminaban con golpes de Estado y la instauración de regímenes autoritarios. Desde la vuelta de la democracia en América Latina, ha sido frecuente la interrupción de los mandatos presidenciales, no ya por la acción de los militares, sino a través de los mecanismos constitucionales. En este sentido,

\footnotetext{
Aragón Reyes, Manuel y López González, José Luis (2000) “Plebiscito”. En

Diccionario electoral (Tomo II). San José: Instituto Interamericano de Derechos Humanos, pp. 981.

Presidencialismo vs. Parlamentarismo. Materiales para el estudio de la Reforma Constitucional en la Argentina. Buenos Aires: Eudeba; Linz, Juan José (1990) "Democracia: Presidencialismo o Parlamentarismo ¿Hace alguna diferencia?”. En Linz, Juan José et al. (Ed.) Hacia una democracia moderna. La opción parlamentaria Santiago: Editorial Universidad Católica de Chile; y Linz, Juan José (1994) "Presidential or Parliamentary Democracy: Does It Make a Difference?. En Linz, Juan José y Valenzuela, Arturo The Failure of Presidential Democracy, Vol. 1, The Johns Hopkins University Press, pp. 3-87.
} 
cabe teorizar aspectos que hacen a la inestabilidad política en los regímenes presidenciales, las crisis institucionales y los recursos constitucionales disponibles para sortear tales ocasiones. En este artículo se sostiene que las crisis institucionales que culminan con un mandato presidencial deben ser pensadas desde la teoría de las caídas presidenciales y, sobre todo, teniendo en cuenta las distintas vías que ofrecen los mecanismos constitucionales para superar los graves momentos que ponen en riesgo a la democracia.

La literatura acerca de las interrupciones o las caídas presidenciales desarrollada en los últimos tiempos ha tratado de dar cuenta de este fenómeno desde diversas perspectivas. En este marco, los autores resaltaron que los desplazamientos han significado caídas de gobiernos, pero dentro del régimen democrático. Mecanismos institucionales fueron los que sellaron la salida de los presidentes, sea a través de la acción del Congreso -impeachment, declaración de incapacidad- o de la renuncia forzada del mandatario. En relación al progreso del juicio político una cuestión clave es si el Presidente goza o no de un "escudo parlamentario" ${ }^{4}$. La renuncia presidencial (forzada) ha sido un mecanismo que, probablemente, se ha utilizado antes de la tercera ola de la democratización ${ }^{5}$.

En un número significativo de casos, los rasgos relevantes de los procesos fueron la protesta social, las manifestaciones y las acciones populares que significaron movilizaciones que determinaron la caída de gobiernos elegidos a través de procedimientos democráticos. En el origen de lo que sería el proceso de caída los autores destacan, entre otros, a la crisis económica, la corrupción, los escándalos políticos y el estilo presidencial que puede acelerar su propia debilidad. También fueron señalados otros factores como el gobierno dividido y la fragmentación partidaria, que incrementan la potencialidad del conflicto $^{6}$, el carácter minoritario de los gobiernos ${ }^{7}$ y la ruptura de las coaliciones que sostienen a los presidentes ${ }^{8}$.

De igual modo, resulta significativo el estilo de liderazgo y el manejo presidencial de la crisis. El estilo confrontacional del mandatario puede ser crucial para sellar su suerte, como parece haber ocurrido en

4 Pérez-Liñán, Aníbal (2007) Presidential Impeachment and the New Political Instability in Latin América Cambridge. New York: Cambridge University Press.

5 Serrafero, Mario Daniel (2016) "La crisis de Venezuela". El Estadista, 18 de noviembre, Buenos Aires: [fecha de visita: 9 de diciembre de 2016]. [Disponible en: http://elestadista. com.ar/?p=11703].

6 Kim, Young Hun y Bahry, Donna (2008) "Interrupted Presidencies in Third Wave Democracies”. The Journal of Politics, 70, 3, pp. 807-822.

$7 \quad$ Negretro, Gabriel (2006) "Minority Presidents and Types of Government in Latin America”. Latin American Politics and Society, 48 3, pp. 63-92.

8 Mejía Acosta, Andrés y Polga-Hecimovich, John (2011a) "Coalition Erosion and Presidential Instability in Ecuador”. Latin American Politics and Society, 53 2, pp. 87-11. 
Ecuador, en 1997, con el Presidente Bucaram9. También se destacó la debilidad -y el aislamiento- del liderazgo presidencial como elemento central de la caída de Fernando de la Rúa, en la Argentina, en 2001. Otros elementos específicos del diseño institucional pueden jugar también un papel significativo. Por ejemplo, en la crisis argentina de 2001, las elecciones intermedias fueron un factor importante que erosionó aún más la legitimidad de un gobierno débil o que había comenzado a presentar problemas de gobernabilidad ${ }^{10}$.

Las rupturas presidenciales mostraron un mayor activismo congresional pues, objetivamente, el Congreso ha aparecido en los desplazamientos institucionales de los presidentes latinoamericanos ${ }^{11}$. Así, por ejemplo, en la última destitución producida en Paraguay, el Congreso utilizó el impeachment para desplazar a Fernando Lugo como una suerte de voto de censura ${ }^{12}$. Las caídas presidenciales configuraron por tanto un nuevo escenario en la región. Sin embargo, las crisis políticas pueden superarse a través de salidas institucionales que parecen haber mostrado un poder congresional incrementado o, según se ha señalado también, cierta "parlamentarización" del presidencialismo.

La revocatoria de mandato, hasta ahora, ha estado totalmente ausente de la teoría y del debate acerca de las interrupciones o caídas presidenciales. No hay duda de que resulta pertinente su inclusión, aunque sean pocos los países que la cuentan en sus constituciones. En este sentido, y como consta en el cuadro que figura a continuación, dentro de las acciones existentes para enfrentar una crisis económica, política e institucional, además de los mecanismos conocidos (renuncia, juicio político, declaración de incapacidad, etc.) más encuadrables dentro de una accountability horizontal, se agrega entonces la revocatoria presidencial. Única acción que tiene como protagonista al pueblo elector y que refleja una accountability vertical. Este mecanismo en poder de los ciudadanos se suma como una nueva herramienta dispuesta para enfrentar situaciones graves que pueden desatar una sucesión constitucional accidentada, esto es el desplazamiento prematuro del Presidente.

\footnotetext{
9 Pérez-Liñán (2007).

10 Serrafero, Mario Daniel (2002) "Argentina: Rebelión en el granero del mundo". Revista de Occidente, No 251, pp. 19-51; Llanos, Mariana (2010) "Presidential Breakdown in Argentina”. En Presidential Breakdowns in Latin America. Palgrave: Macmillan.

11 Llanos, Mariana y Nolte, Detlef (2006) Los Congresos en América Latina: Legislaturas reactivas, potencialmente activas. México: Cámara de Diputados; Carey, John (2006) "Presidencialismo versus parlamentarismo". PostData, $\mathrm{N}^{\circ} 11$, pp. 121-160.

12 Marsteintredet, Leiv; Llanos, Mariana y Nolte, Detlef (2013) "Paraguay and the Politics of Impeachment". Journal of Democracy, 24 4, pp.110-123.
} 
En la actual crisis venezolana aparecen como alternativas los mecanismos que señala su Constitución, algunos similares a los que se han utilizado en interrupciones presidenciales regionales, como la destitución del Presidente, la renuncia o el abandono del cargo y otros más novedosos como la revocatoria del mandato.

\section{2) LA CONSTITUCión DE VENEZUELA: CAMINOS PARA PONER FIN A UN GOBIERNO}

En la Constitución de Venezuela de 1999 (como se señala más adelante) se estableció un presidencialismo poderoso y un fuerte papel de los militares en la vida política, modelo que Biscaretti di Ruffia ${ }^{13}$ señalaba como propio de América Latina pero antes de la transición a la democracia. El formato constitucional y la dinámica política que adquirió el proceso venezolano, sobre todo a partir de la presidencia de Chávez, fueron acumulando lo que Humberto $\mathrm{Njaim}^{14}$ señaló como un "desastre previsible" de la gobernabilidad del país. Así, el chavismo en el poder fue deteriorando cada vez más la situación política, económica y social de Venezuela hasta llegar a la crisis de gobernabilidad que alcanzó su mayor intensidad en 2016 y que al momento de escribir estas páginas continúa.

En la Constitución de Venezuela de $1999^{15}$, son varios los caminos que permiten poner fin a un gobierno. El artículo $233^{\circ}$ los menciona, como así también dispone el reemplazo del Presidente a través de elecciones hasta el cuarto año de mandato. Contrariamente, en el quinto y en el sexto año del periodo, lo sucede el vicepresidente.

El mencionado artículo $233^{\circ}$ estipula como faltas absolutas del Presidente de la República: su muerte, su renuncia, o su destitución decretada por sentencia del Tribunal Supremo de Justicia, su incapacidad física o mental permanente certificada por una junta médica designada por el Tribunal Supremo de Justicia y con aprobación de la Asamblea Nacional, el abandono del cargo, declarado como tal por la Asamblea Nacional, así como la revocación popular de su mandato.

\footnotetext{
13 Biscaretti di Ruffia, Paolo (2000) Introducción al Derecho Constitucional Comparado, México: Fondo de Cultura Económica, pp. 189.

14 Njaim, Humberto (2005) "La gobernabilidad en Venezuela: un desastre previsible". En Valadés, Diego Gobernabilidad y constitucionalismo en América Latina, México: Universidad Nacional Autónoma de México, pp. 253-274.

15 Asamblea Nacional. 30 de diciembre de 1999. "Constitución de la República Bolivariana de Venezuela”. Gaceta Oficial Nº 36.860.
} 
En cuanto al reemplazo del primer mandatario, el mismo artículo dispone que, cuando se produzca la falta absoluta del Presidente electo antes de tomar posesión, se procederá a una nueva elección universal, directa y secreta dentro de los treinta días consecutivos siguientes. Mientras se elige y toma posesión el nuevo Presidente, se encargará de la presidencia de la República el Presidente de la Asamblea Nacional. Si la falta absoluta del Presidente de la República se produce durante los primeros cuatro ańos del período constitucional, se procederá a una nueva elección universal, directa y secreta dentro de los treinta días consecutivos siguientes. Mientras se elige y toma posesión el nuevo Presidente, se encargará de la presidencia de la República el vicepresidente ejecutivo. En los casos anteriores, el nuevo Presidente/a completará el período constitucional correspondiente. Si la falta absoluta se produce durante los últimos dos años del período constitucional, el vicepresidente ejecutivo asumirá la presidencia de la República hasta completar dicho período.

Cabe profundizar en cada una de estas faltas absolutas del Presidente mencionadas en la Constitución venezolana, a saber:

\section{(2.1.) MUERTE}

La muerte del Presidente constituye siempre una crisis institucional más allá de que esta causal obedezca a razones biológicas o mejor dicho "no políticas", aunque la historia muestra no pocos casos de magnicidios. La muerte es un hecho que pone fin al gobierno, tanto en sistemas democráticos como autoritarios y, en estos últimos, tiene una importancia significativa. Baste recordar el fallecimiento de Francisco Franco, en 1975, que puso punto final al régimen autoritario español. En las dictaduras la muerte fue, en numerosas ocasiones, el punto final de la experiencia autoritaria. También la muerte fue importante en regímenes democráticos, tanto presidenciales como parlamentarios. En la región cabe recordar el fallecimiento en el poder de Juan Domingo Perón, en Argentina en 1974, o el suicidio de Getulio Vargas en Brasil, en 1954. Y desde la redemocratización el fallecimiento del Presidente de Ecuador, Jaime Roldós (1985) y de Tancredo Neves en Brasil (1985).

Debe destacarse que la crisis venezolana tuvo un punto de inflexión con la muerte de Hugo Chávez el 5 de marzo de 2013, quien estaba afectado de un cáncer. Debe recordarse que en Venezuela, además de Chávez, murieron en la presidencia Francisco Linares Alcántara, en 1878, el dictador Juan Vicente Gómez, en 1935, y fue asesinado Carlos Delgado Chalbaud (1950) siendo el único magnicidio presidencial en ese país. 


\section{(2.2.) RENUNCIA}

En las constituciones se suele hablar solo de renuncia y, en realidad, debería desplegarse el concepto con mayor amplitud. Según el diccionario de la Real Academia Española la renuncia es la "dimisión o dejación voluntaria de algo que se posee, o del derecho a ello" 16 . Solo cuando la acción es voluntaria sería una renuncia. Pero la realidad política presenta matices en los comportamientos y acciones y en el contexto de los hechos que hace falta reflejar.

Pueden distinguirse distintos tipos de acciones encuadrables en el término genérico de renuncia, pero con sus necesarias aclaraciones y marcadas diferencias. Así podríamos distinguir entre: la renuncia voluntaria, la renuncia forzada que puede ser inmediata o postergada, la renuncia rechazada, la amenaza de renuncia y la falsa renuncia. Es esta una primera y provisoria distinción que podrá ser modificada por ulteriores investigaciones, pero que resulta útil hasta tanto se incremente el conocimiento sobre la materia.

Las renuncias voluntarias son decididas por el renunciante de manera más o menos autónoma y los factores externos no parecen ser la clave de la decisión. Las renuncias forzadas son motivadas por el contexto de hechos conflictivos o graves que imponen al Presidente una decisión no querida, sea para evitar el empeoramiento acelerado de la situación política o social o bien porque el fin de su gestión aparece como horizonte inexorable e inminente. La renuncia forzada puede ser más o menos inmediata al desencadenamiento de los hechos, o bien postergada si el Presidente considera que puede extender un poco más su mandato anunciando la fecha futura de su renuncia e intentando lograr una provisoria descompresión de la situación de riesgo. La renuncia forzada postergada suele ir acompańada del llamado a elecciones anticipadas. La renuncia rechazada ocurre cuando el Presidente presenta su dimisión frente al órgano correspondiente -generalmente el Congreso- y es desestimada, logrando así el Presidente confirmar la "confianza" del Legislativo. La amenaza de renuncia es una estrategia que nunca persigue la resignación del cargo, sino el fortalecimiento del liderazgo presidencial y la falsa renuncia encubre, en realidad, un hecho de destitución ${ }^{17}$.

\footnotetext{
16 Real Academia Española (2016) "Diccionario de la Lengua Española" [fecha de visita: 28 de diciembre de 2016].

[Disponible en: http://dle.rae.es/?id=Vyqz9zm]

17 Serrafero, Mario Daniel (2014) "Flexibilización del presidencialismo en América Latina: ¿un fenómeno nuevo?". Revista de Estudios Políticos, N 163, pp. 67-99.
} 
La mayoría de las renuncias en América Latina han sido forzadas. Los presidentes tuvieron que dejar el poder por situaciones de crisis, presiones políticas y, generalmente, movilizaciones y protestas ciudadanas. Por ejemplo, Alfonsín (1989) y De la Rúa (2001) en la Argentina; Sánchez de Losada (2003) y Carlos Mesa (2005), ambos en Bolivia. En 2015 renunció Otto Pérez Molina, Presidente de Guatemala, acusado por delitos de corrupción. En Venezuela también renunciaron presidentes a lo largo de su historia. Por ejemplo José María Vargas (1836) y José Tadeo Monagas (1858).

El abogado constitucionalista José Vicente Haro ${ }^{18}$ considera que todas las vías planteadas en el debate público sobre la salida de la crisis de 2016 eran engorrosas y algunas, como el referéndum revocatorio, hasta riesgosas, y podían tardar en concretarse entre seis meses y un año, o más. A su juicio era mucho tiempo para un país donde la gente se estaba muriendo de hambre por falta de comida o por escasez de medicinas y tratamientos médicos. Afirmaba que la renuncia de Maduro hubiera sido la vía más rápida. En base al referido artículo $233^{\circ}$ señalaba que la renuncia debía hacerse por escrito, pudiendo haber asumido el Presidente de la Asamblea Nacional y llamarse a elecciones en treinta días.

Efectivamente, en varias oportunidades se pretendió forzar la renuncia del Presidente Maduro, pero sin éxito. Principalmente se recurría a las protestas contra el gobierno a través de manifestaciones callejeras, por ejemplo entre febrero y mayo de 2014. Tampoco tuvo éxito la campaña nacional de la opositora Mesa de Unidad Democrática (MUD), en marzo de 2016, que exigía la renuncia de Maduro.

\section{(2.3.) ABANDONO DEL CARGO}

Esta causal aparece también en el artículo $233^{\circ}$ de la Constitución y dice que el abandono del cargo debe ser declarado como tal por la Asamblea Nacional. En otros países de la región también existe. Se aplicó en el caso del Presidente ecuatoriano Lucio Gutiérrez, en 2005. El Congreso lo destituyó por abandono del cargo, de acuerdo a lo prescripto por el artículo $167^{\circ}$ de la Constitución. La situación del Ecuador era caótica en el marco de los sucesos conocidos como la "Revolución de los Forajidos",

\footnotetext{
18 Acevedo, Génesis (2016) "7 salidas para salir de la crisis explicadas por un constitucionalista”. El tubazo digital, 2 de marzo [fecha de visita: 28 de diciembre de 2016].

[Disponible en: http://www.eltubazodigital.com/noticias-de-venezuela/7-salidas-para-salirde-la-crisis-explicadas-por-un-constitucionalista/].
} 
pero el Congreso destituyó al Presidente sin cumplir los requisitos constitucionales pertinentes.

En la crisis venezolana de 2016, como se verá más adelante, también se intentó poner fin al mandato de Maduro a través de esta causal. El argumento era que el Presidente había hecho abandono del ejercicio de sus atribuciones y obligaciones constitucionales, principalmente varias de las establecidas en el artículo $236^{\circ}$ de la Constitución de Venezuela. El gran atractivo de esta figura es que podría declararse por mayoría de la Asamblea Nacional y sin intervención alguna del Tribunal Supremo de Justicia.

\section{(2.4.) INCAPACIDAD FÍSICA O MENTAL}

Esta causal estuvo presente ya en las constituciones latinoamericanas del siglo XIX, es decir, desde los comienzos del presidencialismo latinoamericano. Existieron ocasiones en que dicho mecanismo fue invocado para derrocar a presidentes, como los casos de Manuel Estrada Cabrera en Guatemala en 1920 y Leonardo Argüello en Nicaragua, en $1947^{19}$. En América Latina se ha intentado remover a presidentes por este motivo en casos en que, por ejemplo, no era viable el juicio político al no contarse con los votos necesarios para su destitución. Así ocurrió, infructuosamente, con la ex Presidenta argentina María Estela Martínez de Perón durante su gobierno que concluyó, finalmente, con un golpe de Estado en 1976. En tiempos más recientes el Presidente ecuatoriano Abdalá Bucaram fue destituido por incapacidad mental, en 1997, por un Legislativo que no alcanzaba los votos necesarios para destituirlo a través de un juicio político.

La Constitución venezolana establece que la incapacidad puede ser física o mental, debe ser de carácter permanente y estar certificada por una junta médica designada por el Tribunal Supremo de Justicia y con aprobación de la Asamblea Nacional. La prueba de esta causal es relevante, entonces, para que se produzca el desplazamiento del presidente.

\section{(2.5.) DeSTITUCIÓN}

De acuerdo al referido artículo $233^{\circ}$ de la Constitución venezolana, la destitución del Presidente por el Supremo Tribunal de Justicia es una forma de ausencia absoluta del mandatario. La Ley Fundamental señala el

19 Pérez-Liñán (2007). 
procedimiento en el artículo $266^{\circ}$, que en su parte pertinente dice: "Son atribuciones del Tribunal Supremo de Justicia: 1. Ejercer la jurisdicción constitucional conforme al Título VIII de esta Constitución. 2. Declarar si hay o no mérito para el enjuiciamiento del Presidente o Presidenta de la República o quien haga sus veces, y en caso afirmativo, continuar conociendo de la causa previa autorización de la Asamblea Nacional, hasta sentencia definitiva" 20 .

En Venezuela no existe entonces el juicio político o impeachment, donde el Congreso acusa y juzga al mandatario. Quien lo destituye es el Supremo Tribunal de Justicia, aunque debe contar con la autorización previa de la Asamblea Nacional para llevar adelante el proceso contra el Presidente.

En América Latina existen procedimientos parlamentarios donde son las Cámaras las que deciden el apartamiento del Presidente, pero también hay diseños mixtos que prevén la actuación del Legislativo y del Poder Judicial. Desde la vuelta de la democracia, contrariamente a lo señalado en su momento por Juan Linz ${ }^{21}$, el juicio político fue una herramienta importante que puso fin a varios gobiernos de la región en situación de severas crisis políticas, económicas y sociales. Entre los casos de juicios políticos cabe referir los siguientes: Fernando Collor de Mello, enjuiciado en Brasil en 1992, renunció antes de que el Senado lo destituyera. También en Brasil, en 2016, Dilma Rousseff fue destituida por el Senado. En Paraguay, en 1999, el Presidente Raúl Cubas Grau fue enjuiciado políticamente y renunció antes de ser destituido. También en Paraguay, Fernando Lugo fue removido del cargo en 2012. Los presidentes que han sido destituidos o se les ha iniciado un impeachment han considerado que fueron víctimas de conspiraciones o golpes de Estado. Incluso en algunos casos el debate y la polémica dividieron países e intelectuales, por ejemplo, en las destituciones de Fernando Lugo y de Dilma Rousseff.

En Venezuela existió un caso en que se puso en marcha la destitución del Presidente. Fue en 1993 con Carlos Andrés Pérez, electo por Acción Democrática $(\mathrm{AD})^{22}$. La Constitución de Venezuela -vigente en aquel entonces- establecía en su artículo $215^{\circ}$ que eran atribuciones de la Corte Suprema de Justicia: 1. Declarar si hay o no mérito para el enjuiciamiento

AN. Gaceta Oficial N 36.860-1999.

Linz (1990).

Acción Democrática. Partido fundado el 13 de septiembre de 1941 bajo el gobierno de Medina Angarita. Representa y defiende los intereses de los sectores sociales más vulnerables, y a los venezolanos progresistas comprometidos con una Venezuela más justa, igualitaria y comprometida con los valores democráticos. [fecha de visita: 28 de diciembre de 2016]. [Disponible en: http://acciondemocratica.org.ve] 
del Presidente de la República o quien haga sus veces, y, en caso afirmativo, continuar conociendo la causa, previa autorización del Senado, hasta la sentencia definitiva.

La democracia venezolana había tenido un florecimiento económico debido a la producción petrolera ${ }^{23} \mathrm{y}$ a sus cuantiosos ingresos en divisas; sin embargo, la "fiesta económica" había llegado a su fin mucho antes del segundo acceso al poder del Presidente Pérez y el sistema político evidenciaba grandes déficits. La corrupción estaba enquistada en todo el sistema político. La vida laboral, gremial, económica y social se partidizó en extremo. La partidización del Estado y de la sociedad recrudeció la corrupción. La presidencia de Pérez se desgastaba aceleradamente y su legitimidad mermaba. La deteriorada imagen del Presidente no llegaba al 10\% de aprobación ciudadana.

Las alternativas no eran muchas: golpe de Estado, renuncia del Presidente o destitución. Desde el poder, se puso en marcha la tercera vía y Ramón Escovar Salom, fiscal general de Venezuela, solicitó a la Corte Suprema de Justicia el procesamiento de Pérez por malversación de fondos públicos y peculado ${ }^{24}$, el 11 de marzo de 1993. Todos los sectores políticos presionaban para la renuncia de Pérez o bien para que se adelantaran las elecciones presidenciales y legislativas que debían celebrarse en diciembre de 1993.

El 20 de mayo se reunieron los integrantes de la Corte. El cuerpo se expidió positivamente en relación con el informe de su Presidente sobre la existencia de mérito para llevar adelante el juicio contra Pérez. El Senado había sido convocado al día siguiente para tratar la autorización o no del juzgamiento. Se descontaba tal autorización y la suspensión automática del Presidente hasta tanto recayera el fallo de la Corte.

Ante tal cuadro, la misma noche del 20 de mayo el Presidente, por cadena de radio y televisión, anunciaba su "alejamiento temporal", que no implicaba la renuncia formal a cargo. Pocas horas después se decidía en la Cámara Alta la suspensión del Presidente para ser juzgado por la Corte Suprema. Por mandato constitucional, Octavio Lepage, titular del Senado, se hacía cargo interinamente de la presidencia.

Finalmente, Ramón José Velásquez juró el 5 de junio de 1993 como Presidente de Venezuela. En la histórica sesión conjunta de las Cámaras

23 Sobre el papel del petróleo y los pactos institucionales en la transición ver LyNn KarL, Terry (1988) "El petróleo y los pactos políticos: La transición a la democracia en Venezuela". En O’Donnell, Guillermo; Schmitter, Philippe y Whitehead, Lauraence Transiciones desde un gobierno autoritario, Tomo 2. Buenos Aires: Paidós.

24 Se trataba de la utilización indebida de gastos reservados correspondientes a seguridad y defensa del Estado, cuya suma superaba los 17 millones de dólares. 
votaron a su favor 205 de los 236 parlamentarios y fue así que Velásquez surgió como el "presidente del consenso" 25 , siendo respaldado por los representantes de AD y de $\mathrm{COPEI}^{26}$. El círculo del proceso institucional se cerró con la destitución de Pérez del cargo presidencial, mediante procedimientos institucionales llevados a cabo por el Congreso.

\section{(2.6.) Asamblea Nacional Constituyente}

Existen otros caminos que podrían tenerse presentes y que no son los que establece el artículo $233^{\circ}$ de la Constitución. Por ejemplo, la convocatoria a una Asamblea Nacional Constituyente, que puede transformar el Estado y crear un nuevo régimen político. Dice el artículo $347^{\circ}$ que el pueblo de Venezuela es el depositario del poder constituyente originario. En ejercicio de dicho poder, puede convocar una Asamblea Nacional Constituyente con el objeto de transformar el Estado, crear un nuevo ordenamiento jurídico y redactar una nueva Constitución.

El siguiente artículo señala quienes tienen la iniciativa de convocatoria a la Asamblea Constituyente: el Presidente de la República en Consejo de Ministros; la Asamblea Nacional, mediante acuerdo de la dos terceras partes de sus integrantes; los Consejos Municipales en Cabildo, mediante el voto de las dos terceras partes de los mismos; o el quince por ciento de los electores inscritos en el Registro Civil y Electoral.

La convocatoria a una Asamblea Nacional Constituyente también fue invocada como camino alternativo de resolución de la crisis de 2016. Pero como se verá más adelante, fue el propio Maduro quien eligió esta vía como mecanismo para intentar reafirmar su poder en medio de una situación crítica, que terminó virando hacia la ingobernabilidad.

Cabe recordar que Chávez había promovido la convocatoria de una Constituyente ni bien juró como Presidente por primera vez, aunque la misma no figuraba en la Constitución de 1961. El proceso llevado a cabo tuvo al Pre-

25 Además de su trayectoria legislativa, Velásquez se había desempeñado como secretario de la presidencia de Rómulo Betancourt y secretario de comunicación de la presidencia de Rafael Caldera.

26 Comité de Organización Política Electoral Independiente. COPEI nace como una alternativa al socialismo, y se proclama como tal desde su misma fundación el 13 de enero de 1946. Surgió para brindar a los venezolanos una plataforma política para las elecciones de la Asamblea Constituyente del 27 de octubre de 1946. De allí se deriva su nombre fundacional. No obstante, su consolidación definitiva como partido político surge propiamente en su III Convención Nacional, realizado en marzo de 1948, en la cual, se definió el partido como Socialcristiano. Partido socialcristiano de Venezuela. Somos los representantes de la Democracia Cristiana mundial [fecha de visita: 28 de diciembre de 2016].

[Disponible en: http://partidocopei.net/] 
sidente como protagonista y diseńador de la empresa constituyente. La asamblea fue integrada por una abrumadora mayoría de sus seguidores y se instauró un sistema presidencialista concentrado y desequilibrado en su favor ${ }^{27}$.

Como señala Brewer-Carías, esta Constitución no fue el producto de una tarea consensuada entre los diferentes sectores del país, sino una imposición del Presidente quien modeló un régimen político a su medida. Su perspectiva crítica refiere también al producto y contenido de la nueva Constitución. Dice este autor:

La Constitución de 1999, que resultó del trabajo de la Asamblea Nacional Constituyente, en consecuencia y lamentablemente, fue una Constitución que diseñó un sistema de concentración del poder en el Ejecutivo, con una clara exclusión respecto de los partidos politicos, que funciona en un sistema politico de presidencialismo extremo y exacerbado, montado sobre un militarismo constitucional nunca antes conocido en el pais, y en una forma de Estado signada por el centralismo, en el cual la Federación no es más que una simple palabra sin contenido alguno, y sin posibilidad efectiva alguna de provocar descentralización politica. Ese Estado, además, por la concentración del poder, ha originado un poder judicial sometido y dependiente, que no garantiza la vigencia efectiva de los derechos humanos. Por otra parte, el esquema, además, está montado sobre un estatismo extremo que se ha alimentado por la riqueza petrolera estatal, lo que en definitiva imposibilita la participación política, la cual solo puede darse cuando el poder está cerca del ciudadano y sus comunidades, actuando con autonomía ${ }^{28}$.

Finalmente Bejarano ${ }^{29}$ señala que la nueva Constitución no solo incrementó los poderes presidenciales y debilitó al Legislativo, sino que también habilitó el mayor protagonismo del estamento militar.

\section{(2.7.) ENMiENdA CONSTITUCiONAL}

Otra de las vías para habilitar la salida anticipada de un Presidente podría ser la enmienda constitucional. De acuerdo al artículo $340^{\circ}$ de la

27 Combellas, Ricardo (2002) "La Constitución de 1999 y la reforma política: implicaciones para la gobernabilidad democrática", VII Congreso Internacional del CLAD sobre la Reforma del Estado y de la Administración Pública, Lisboa, Portugal, 8-11 Oct.

28 Brewer-Carías, Allan (2007) "El inicio del proceso constituyente en Ecuador en 2007 y las lecciones de la experiencia venezolana de 1999”, Iuris dictio Año 12. Vol 14, pp. 111.

29 Bejarano, Ana María (2005) “Transformaciones de la democracia en Venezuela: una lectura crítica de la constitución de 1999”, Desafíos, vol. 12, enero-junio, pp. 132-144 
Ley Fundamental venezolana, la enmienda tiene por objeto la adición o modificación de uno o varios artículos de la Constitución, sin alterar su estructura fundamental.

El artículo $341^{\circ}$ establece la forma en que deben tramitarse tales enmiendas a la Constitución: 1. La iniciativa podrá partir del quince por ciento de los ciudadanos inscritos en el Registro Civil y Electoral; o de un treinta por ciento de los integrantes de la Asamblea Nacional o del Presidente de la República en Consejo de Ministros. 2. Cuando la iniciativa parta de la Asamblea Nacional, la enmienda requerirá la aprobación de esta por la mayoría de sus integrantes y se discutirá, según el procedimiento establecido en esta Constitución para la formación de leyes. 3. El Poder Electoral someterá a referendo las enmiendas a los treinta días siguientes a su recepción formal. 4. Se considerarán aprobadas las enmiendas de acuerdo con lo establecido en esta Constitución y en la ley relativa al referendo aprobatorio. 5. Las enmiendas serán numeradas consecutivamente y se publicarán a continuación de esta Constitución sin alterar el texto de esta, pero anotando al pie del artículo o artículos enmendados la referencia de número y fecha de la enmienda que lo modificó.

En referencia a la grave crisis atravesada por Venezuela transcurrida la mitad del primer mandato presidencial de Nicolás Maduro, sectores de la oposición plantearon la reducción del período presidencial de 6 a 4 años, la eliminación de la reelección indefinida y el recorte de 12 a 6 ańos del período de los magistrados del Tribunal Supremo de Justicia. Según el Presidente de la Asamblea Nacional en 2016, Henry Ramos Allup, la enmienda constitucional es "el mecanismo más simple, eficiente, seguro, y menos gravoso" 30 para alejar del cargo al primer mandatario. Sin embargo, la enmienda recién tendría efectos finalizado el gobierno de turno, ya que no es retroactiva. En este caso puntual, entraría en vigencia terminada la presidencia de Nicolás Maduro en 2019.

\section{(2.8.) ReVocatoria de Mandato}

En Venezuela, la revocatoria de mandato se introdujo por primera vez en la Constitución Nacional impulsada por el entonces presidente Hugo Chávez Frías, aprobada en 1999. La Constitución de la República

30 Briceno Pérez, Irving (2016) “Enmienda constitucional produce cambio de régimen pero puede extenderse hasta 2019". Efecto Cocuyo, 6 de diciembre [fecha de visita: 28 de diciembre de 2016]. [Disponible en: http://efectococuyo.com/politica/la-enmienda-constitucional-cambia-el-regimen-pero-puede-extenderse-hasta-2019]. 
Bolivariana de Venezuela de $1999^{31}$, enmendada en $2009^{32}$ para permitir la reelección indefinida de las autoridades electivas, desde su preámbulo anuncia el fin supremo de refundar la República para establecer una sociedad democrática, participativa y protagónica.

En el artículo $5^{\circ}$ reconoce la soberanía como facultad que reside intransferiblemente en el pueblo y distingue entre su ejercicio directo (en la forma prevista en esa Constitución y en la ley) e indirecto (mediante el sufragio, por los órganos que ejercen el Poder Público). Postula además un gobierno de la República y de las entidades políticas que la componen siempre democrático, participativo, electivo, descentralizado, alternativo, responsable, pluralista y de mandatos revocables (art. $6^{\circ}$ ).

Reconoce a la revocatoria de mandato, la elección de cargos públicos, el referendo, la consulta popular, la iniciativa legislativa constitucional y constituyente, el cabildo abierto y la asamblea de ciudadanos, como medios de participación y protagonismo del pueblo en ejercicio de su soberanía política, cuyas decisiones son vinculantes $\left(\operatorname{art.} 70^{\circ}\right.$ ).

La revocatoria de mandato se dispone para todos los cargos y magistraturas de elección popular a nivel nacional, regional y local, siendo esta la primera constitución en otorgar tal amplitud de acción a dicho mecanismo, seguida, bastante más tarde, por la de Ecuador (2008) y la de Bolivia (2009). El artículo $197^{\circ}$ estipula que los diputados a la Asamblea Nacional deben dar cuenta anualmente de su trabajo a los electores de su circunscripción y están sometidos al referendo revocatorio del mandato.

La revocatoria en Venezuela no requiere una justificación para ser activada. Puede iniciarse una vez transcurrida la mitad del período para el cual fue elegido el funcionario y a solicitud de un número no menor al $20 \%$ de los electores inscritos en la circunscripción del funcionario en cuestión $\left(\operatorname{art} .72^{\circ}\right)$. La decisión sobre la permanencia en el cargo del representante sometido a revocatoria se toma mediante un referendo popular en el que pueden participar todos los electores de la circunscripción por la cual fue elegido. Cuando igual o mayor número de electores que eligieron al funcionario vote a favor de la revocatoria, siempre que concurra al referendo un número de electores igual o superior al $25 \%$ de los inscritos, se considera revocado su mandato y se procede de inmediato a cubrir la falta según la Constitución (art. $72^{\circ}$ ). Cabe recordar que en este país el voto es no obligatorio para todos los casos y que para ser elegido Presidente se requiere reunir solamente la mayoría de los votos válidos

31 AN. Gaceta Oficial N 36.860-1999.

32 Asamblea Nacional. 20 de febrero de 2009. "Constitución de la República Bolivariana de Venezuela con la enmienda No 1”. Gaceta Oficial Extraordinaria N ${ }^{\circ} 5.908$. 
emitidos (art. 228\%). Si la sustitución del mandatario revocado debe decidirse, según lo previsto en la normativa, a través de una nueva elección, esta tiene que llevarse a cabo en una votación posterior, separada de la del referendo revocatorio.

El artículo $233^{\circ}$ enumera entre las faltas absolutas del Presidente la revocación popular de su mandato, que motivan a su reemplazo por elecciones o por su vicepresidente. En caso de que la revocatoria sea aprobada bajo las condiciones estipuladas, prosigue el cese inmediato del correspondiente funcionario. Si el revocado es el Presidente y se encuentra en su cuarto año de mandato (que dura 6 años), se llama a elecciones para completar el período, mientras tanto lo reemplaza el vicepresidente (que es designado y destituido no por voto popular sino por el propio Presidente). Si en cambio se lo revoca en el quinto o sexto ańo, completa el período el vicepresidente ejecutivo, sin llamarse a elección popular. Durante el período para el cual fue elegido el funcionario no puede hacerse más de una solicitud de revocación de su mandato (art. $72^{\circ}$ ).

Luego de varias reglamentaciones, el 6 de septiembre de 2007, el Consejo Nacional Electoral (CNE) aprobó la Resolución No 0709062770 "Normas para Regular el Procedimiento de Promoción y Solicitud de Referendos Revocatorios de Mandatos de Cargos de Elección Popular" 33 , que se aplicó en el procedimiento iniciado en 2016 contra el Presidente Nicolás Maduro. Esta resolución añadió nuevos requisitos a los establecidos en la Constitución ${ }^{34}$.

La norma reglamenta los procesos relativos a la promoción y solicitud de referendos revocatorios de mandatos de elección popular (art. $1^{\text {o) }}$. Dispone que la solicitud de referéndum debe hacerla una agrupación de ciudadanos o una organización con fines políticos nacionales o regionales, y no directamente el $20 \%$ de los electores (a título individual) como establece la Constitución.

Las agrupaciones de ciudadanos pueden constituirse una vez transcurrido la mitad del período para el cual fue elegido el funcionario en cuestión y mantienen su vigencia hasta la culminación del proceso refrendario para el cual se constituyeron (art. $7^{\circ}$ ). La cantidad de adhesiones necesarias para conformar agrupaciones ciudadanas es del 1\% de la población

33 Consejo Nacional Electoral. 18 de diciembre de 2007. Resolución No 070906-2770 "Normas para Regular el Procedimiento de Promoción y Solicitud de Referendos Revocatorios de Mandatos de Cargos de Elección Popular". Gaceta Electoral N 405.

34 LA PATILLA (2016) "La revocatoria del mandato en Venezuela: un procedimiento innecesariamente complejo", 17 de marzo [fecha de visita: 24 de abril de 2016]. [Disponible en: http://www.lapatilla.com/site/2016/3/17/la-revocatoria-del-mandato-en-venezuela-unprocedimiento-innecesariamente-complejo]. 
inscripta en el Registro Electoral del municipio, del Estado o nacional según sea el caso, correspondiente al funcionario a revocar. Para municipios con menos de 10.000 electores se requiere la firma de al menos 100 ciudadanos $\left(\right.$ art. $8^{\circ}$ ). Los promotores cuentan con 30 días para llevar adelante dicha empresa.

También se reconoce el derecho de los electores a promover referendos revocatorios a través de las organizaciones con fines políticos. Para ello las autoridades de las organizaciones deberán ser autorizadas por su máximo órgano de dirección conforme a sus estatutos, y deberán presentar un número de adhesiones de electores inscriptos conforme a lo exigido para la constitución de agrupaciones ciudadanas a los fines de promover la revocatoria de mandato (art. $13^{\circ}$ ).

En cuanto al procedimiento de promoción y solicitud del referendo revocatorio, ratifica lo estipulado por la Constitución respecto del plazo en que puede solicitarse y la cantidad de firmas que debe acompañar la solicitud (art. 15\%). Solo si la solicitud es ratificada por el CNE (para lo cual se establece un procedimiento complejo), empieza el proceso fijado en la Constitución para que el $20 \%$ de los electores exprese su deseo de ir a referéndum. La recepción de manifestaciones de voluntad se realiza por el exiguo plazo de 3 días en los centros establecidos por el CNE (art. 26).

Si la cantidad de firmas alcanza el mínimo requerido, el CNE declara la solicitud como procedente y debe convocar al referendo en los siguientes 3 días. De lo contrario no se le da lugar (art. 29º). El referendo se celebra dentro de los 90 días continuos siguientes a su convocatoria (art. $30^{\circ}$ ): "En total, el procedimiento hasta que el CNE convoque el referéndum toma 228 días, o sea, casi 8 meses, contando los lapsos máximos establecidos por la normativa del CNE" 35 . Ello, en el caso de que no haya demoras extraordinarias (arbitrarias o no) que lo prolonguen aún más, pudiendo favorecer al revocable. Finalmente la normativa dispone que el CNE sea el encargado de confeccionar el Cronograma con los lapsos para el proceso de constitución de las agrupaciones de ciudadanos y para la promoción y solicitud de los referendos revocatorios (art. 31\%). Mientras tanto no entre en vigencia la correspondiente Ley Orgánica de Referendos, aprobada por la Asamblea Nacional el 20 de abril de 2016, rige la normativa descrita.

Cabe aclarar que la revocatoria presidencial es un mecanismo de difícil aplicación debido a la centralidad y relevancia del cargo en juego para un régimen presidencial. Aún así, tanto Venezuela como Bolivia (aunque no ocurrió igual en Ecuador, que también cuenta con este mecanismo)

La Patilla (2016). 
experimentaron cada uno de estos países un caso de aplicación de revocatoria de mandato para destituir a presidentes en ejercicio. Curiosamente, fue contra aquellos presidentes que impulsaron las reformas constitucionales más radicales, y en las que se incorporó por primera vez la revocatoria de mandato. A diferencia de lo que se podría esperar del uso de un mecanismo de revocatoria, los mandatarios resultaron plebiscitados y reforzados en sus cargos.

En Venezuela, un caso previo al de Nicolás Maduro tuvo lugar el 15 de agosto de 2004. Se trató de un referéndum revocatorio dirigido contra el presidente Hugo Chávez, durante su segundo período en el Ejecutivo (2001-2007). El proceso se realizó en medio de un clima de movilización social y de crisis política. Fue impulsado por la oposición para destituir en forma democrática al Presidente, mediante un procedimiento de voto popular previsto en la Constitución vigente de 1999. Paradójicamente, esa Constitución había sido impulsada por el propio Chávez en su primer período presidencial (1999-2001).

La ola de crispación social venía de tiempo atrás. Ya había desencadenado el golpe de Estado del 11 de abril de 2002, ejecutado por la oposición. Restablecido en el cargo, Chávez había tenido que lidiar con el prolongado paro petrolero que afectó a la empresa estatal de Petróleos de Venezuela Sociedad Anónima (PDVSA). El paro reunía a sus opositores junto a un grupo de empresarios y provocó graves consecuencias económicas, políticas y sociales para el país y la población.

Frente a tan oscuro panorama, la Organización de Estados Americanos (OEA) y el Centro Carter de los Estados Unidos, organizaron una mesa de negociación y acuerdo para que el gobierno y la oposición pactasen un cese de la violencia. Si bien no fue observado por las partes, sirvió como antecedente para pactar luego la realización del referéndum.

Tras el fin del paro en 2003, la oposición, agrupada bajo el nombre de la Coordinadora Democrática $(\mathrm{CD})^{36}$, continuó con su protesta activa. En su apoyo se sumaban algunos canales de televisión, la patronal, Fedecámaras ${ }^{37}$, el sindicato Confederación de Trabajadores de Venezuela

36 Coalición de partidos políticos, asociaciones civiles y ONG venezolanas opositoras a la administración de Hugo Chávez, fundada el 17 de octubre de 2002. Buscaba llegar a un acuerdo para la reconstrucción democrática de Venezuela. Reconocía que la salida del poder del Presidente Chávez debía realizarse de cualquier manera con arreglo a las vías y recursos jurídicos de la Constitución Nacional.

37 Es una Asociación Civil sin fines de lucro formada por entidades económicas gremiales privadas integradas por empresarios, personas naturales o jurídicas que conjunta o separadamente, ejerzan la representación de actividades e intereses económicos. [fecha de visita: 19 de mayo de 2015].

[Disponible en: http://www.fedecamaras.org.ve/detalle.php?id=50] 
(CTV), la Iglesia católica y empresarios. Todos ellos con el cometido de forzar la renuncia de Chávez. Tales manifestaciones se topaban, a su vez, con las contramarchas pro-Chávez, desarrolladas en defensa de la continuidad del Presidente.

En medio de tal clima de disputa, las partes aceptaron finalmente lanzar el referéndum de revocatoria, que había sido propuesto por la mesa de negociación y acuerdo. La CD promovió la recolección de firmas para la solicitud. En noviembre, y en tan solo cuatro días (los estipulados en la normativa), los promotores alcanzaron la cifra récord de 3.6 millones de adhesiones. De ese total, 2.4 millones (el mínimo necesario) fueron validadas, aunque tras idas y vueltas del CNE que dudaba de la autenticidad de las firmas. Todo ello, en un clima de desconfianza, violencia y enfrentamiento entre los diversos sectores.

La consulta se celebró el 15 de agosto de 2004 . Hubo una muy alta concurrencia en las urnas: el 69,92\% del padrón, porcentaje aún más destacado si se toma en cuenta que el voto en todas sus modalidades es no obligatorio en ese país. El resultado fue el rechazo a la destitución, avalado por un $59.06 \%$ de los votos válidos que optaron por el "No" contra el $40.64 \%$ que prefirió destituirlo ("Sî"). El presidente Chávez fue ratificado en el cargo, aunque entre fuertes acusaciones de fraude, luego desestimadas por los organismos veedores (el Carter Center y la OEA).

Luego del referéndum se aquietaron los disturbios, el Presidente salió fortalecido y el frente opositor fue desarmado: la alianza de los diferentes grupos se quebró, se disolvió la CD y, en general, los contrarios a Chávez perdieron fuerza de convocatoria. Algunos medios de comunicación dejaron de participar en la contienda política.

En este caso, la revocatoria de mandato presidencial, a pesar de haber arrojado un resultado adverso al que se supone se orienta por definición este mecanismo (revocar mandatos), permitió superar una crisis institucional, aun cuando, paradójicamente, ello no fuera a través de la destitución del Presidente cuestionado sino por su ratificación ${ }^{38}$.

El otro caso de revocatoria presidencial en América Latina se llevó a cabo el 10 de agosto de 2008 en Bolivia, para decidir sobre la continuidad del presidente Evo Morales y el vicepresidente Álvaro García Linera transcurrida la mitad de su primer período de gobierno (2006-2010). La consulta también alcanzó a 8 de los 9 prefectos departamentales. Esta vez, la iniciativa de la consulta surgió del propio Presidente, en un intento

38 Eberhardt, María Laura (2016b) "La Revocatoria de Mandato en Venezuela y su diseño institucional: el caso Hugo Chávez (2004)”. Revista Brasileira de Sociología, Vol. 04 N. 8 Jul. Dez; pp. 59-92. 
por frenar la oposición autonomista de varios departamentos. Al igual que ocurrió con Hugo Chávez, Morales y su vice fueron ratificados. Con voto obligatorio y una participación del $83,3 \%$, los resultados dieron un $67,41 \%$ de los sufragios a su favor (el "Sî") y el $32,59 \%$ en contra.

Los 6 prefectos oficialistas de los departamentos de Oruro, Potosí, Tarija, Santa Cruz, Pando y Beni mantuvieron sus puestos, mientras que los prefectos opositores de La Paz y Cochabamba fueron revocados. Como en Venezuela, el referendo revocatorio resultó favorable al Presidente, sellando su continuidad y aquí también la de sus aliados ${ }^{39}$.

\section{3) LA CRISIS VENEZOLANA DE 2016. Diversas VÍAS DE SALIDA anticipada del presidente Nicolás Maduro. La REVOCATORIA PRESIDENCIAL}

La crisis institucional de Venezuela de 2016 se fue profundizando desde hace mucho tiempo. Quizá la muerte de Chávez significó el punto de cierre del relato colorido de la revolución bolivariana y comenzaría con el sucesor, Nicolás Maduro, el oscuro plano inclinado hacia el fin. No fue otra cosa que una profunda crisis de gobernabilidad signada por el colapso económico, la emergencia social y la división de la sociedad, lo que crispó una situación percibida como fin de ciclo. Chavismo y antichavismo se enfrentaron en un combate que pretendía utilizar las herramientas institucionales para justificar sus posiciones. Como se ve a continuación, distintos fueron los laberintos que recorrió la oposición para encontrar la salida de la crisis.

La coalición opositora MUD anunció en diciembre de 2015, que en el primer semestre del siguiente año buscaría un referendo revocatorio del mandato del Presidente: el cambio político en Venezuela no podía esperar a las elecciones presidenciales de 2019. Según los plazos legales, el referendo podría tramitarse desde abril de 2016.

La búsqueda de ese cambio formaba parte de un acuerdo alcanzado en julio de 2015 por los partidos que conformaban la MUD. Sin embargo, antes de intentar el revocatorio o la renuncia de Maduro, la oposición pediría en el Parlamento soluciones a la grave crisis económica y social y una amnistía para los presos políticos.

39 Eberhardt, María Laura (2016a) "La Revocatoria de Mandato en Bolivia. Su diseño institucional. El caso Evo Morales (2008)”. Acciones e Investigaciones Sociales, N³6, pp. 253278. 
Los responsables de la MUD acordaron llevar a cabo una discusión profunda sobre qué mecanismo debían activar para lograr el cambio: una enmienda constitucional que redujera el mandato presidencial a 4 años y prohibiera la reelección inmediata, la renuncia del Presidente, el referendo revocatorio del mandato de Maduro, o una constituyente. El primer objetivo sería lograr la mayoría en la Asamblea Nacional (AN) en las elecciones del 6 de diciembre de 2015. Esta meta fue alcanzada sin inconvenientes.

Según la Constitución venezolana, el referendo revocatorio podría ser tramitado después de que el Presidente cumpliera la mitad de su mandato, lo que en el caso de Maduro ocurriría el 19 de abril de 2016, habiendo asumido en igual fecha de 2013 para reemplazar al fallecido Hugo Chávez.

Poco tiempo atrás, entre febrero y mayo de 2014, el líder del ala radical de la oposición, Leopoldo López, había alentado una alternativa no institucional de reemplazo del Presidente: las protestas contra el gobierno socialista de Maduro que dejaron 43 muertos. Tras ello fue condenado el 10 de septiembre a 13 ańos y 9 meses de cárcel por incitación a la violencia. Su estrategia, denominada "la salida", buscaba forzar la renuncia de Maduro a través de manifestaciones callejeras contra su gestión, marcada por la inseguridad, una aguda escasez de productos básicos y una alta inflación ${ }^{40}$. Luego de 3 ańos y 5 meses en la cárcel, en julio de 2017 el Tribunal Supremo de Justicia (TSJ) habilitó el regreso a su casa para cumplir arresto domiciliario en una señal de acercamiento a la oposición.

Hacia marzo de 2016, la MUD lanzó una contraofensiva política para alcanzar el poder. Se declaró en sesión permanente para elegir el mecanismo más adecuado e inició una campaña nacional orientada a exigir la renuncia del Presidente, decisión con la que también estaban de acuerdo chavistas radicales y un grupo de militares que habían acompańado a Hugo Chávez en el golpe de Estado del 4 de febrero de 1992.

El desencadenante de esta acción fue la Sentencia del TSJ que eliminaba o limitaba el control parlamentario a los poderes públicos, considerado por la oposición como equivalente a un golpe de Estado. En su quinta sentencia desde las elecciones parlamentarias de diciembre, el TSJ decidió que el Parlamento solo podría ejercer su tarea de control (y de forma parcial) respecto del Ejecutivo, y no sobre el resto de los poderes públicos, incluidos los militares y el propio Alto Tribunal.

40 El Deber Mundo (2015) “Oposición venezolana buscará revocatoria de Maduro en 2016”, 10 de noviembre, Santa Cruz de la Sierra [fecha de visita: 4 de marzo de 2006]. [Disponible en: http://www.eldeber.com.bo/mundo/oposicion-venezolana-buscara-revocatoria-maduro. html]. 
Judicialización de la política (las constantes intervenciones del TSJ en contra de las instituciones políticas controladas por la oposición) y politización de la justicia (un TSJ y un CNE que actuaban exclusivamente a favor del primer mandatario) fueron las dos caras de la moneda que el Presidente empleó repetidamente para entorpecer cualquier intento de la oposición por poner en práctica los diversos mecanismos de accountability horizontal (control del Ejecutivo por el Legislativo) y vertical (la revocatoria de mandato) reconocidos, paradójicamente, por la Constitución de Hugo Chávez.

En efecto, desde la derrota electoral revolucionaria en diciembre de 2015, el TSJ había blindado a Maduro, decretando la suspensión de tres diputados opositores de Amazonas (para que la oposición no contase con la fundamental mayoría calificada de los dos tercios), amenazando con decretar nulas las actuaciones de la AN y ordenando la puesta en marcha del decreto de emergencia económica elaborado por el Ejecutivo, pese a la votación contraria del hemiciclo. Las embestidas contra la AN controlada por la oposición no fueron solo judiciales o mediáticas. En torno del Palacio Legislativo recrudeció el hostigamiento y la violencia contra diputados opositores y periodistas.

Asimismo, el presidente Nicolás Maduro restringió por decreto las facultades del Parlamento para aprobar mociones de censura y remover a sus ministros, alegando que ello agravaría la crisis económica: "Se restringe y difieren (...) las mociones de censura que pudiera acordar la AN contra los ministros o el vicepresidente ejecutivo, en las cuales solicitaren su remoción, hasta tanto cesen los efectos del decreto de emergencia económica" ${ }^{41}$. La medida se tomó luego de que la mayoría opositora en el Legislativo destituyera al ministro de alimentación, Rodolfo Marco Torres, al votar una moción de censura que lo responsabilizaba de la grave escasez de alimentos.

La oposición estudió varias posibilidades. Amenazó incluso con convocar a una Asamblea Nacional Constituyente. Sin embargo, esta sería la última opción, ya que la mayoría de los partidos apostaba por la enmienda constitucional que recortaría el período presidencial a cuatro ańos con una sola reelección. La agrupación Primero Justicia y el entonces gobernador del Estado de Miranda, Henrique Capriles, preferían el referéndum revocatorio, convencidos de que el TSJ evitaría la retroactividad de la enmienda.

41 Periódico LA TARDE (2016) “Arrancó revisión de firmas para revocatoria Maduro", 5 de mayo [fecha de visita: 5 de mayo de 2016]. [Disponible en: http://www.latarde.com/actuali$\mathrm{dad} /$ mundo/169662-arranco-revision-de-firmas-para-revocatoria-de-maduro]. 
Mientras tanto, la MUD siguió debatiendo los detalles de su propuesta. El referéndum revocatorio parecía ser la opción más plausible, ya que dependía del voto popular. La mitad del mandato de Maduro, se había cumplido el 19 de abril. Para ello, la oposición debía primero reunir el $1 \%$ de firmas respecto del padrón y luego 3,9 millones de firmas $(20 \%$ del padrón). Una vez presentadas, el Consejo Nacional Electoral (CNE) tenía 15 días para revisarlas, pudiendo rechazarlas y solicitar nuevas firmas, como ocurrió con el proceso revocatorio de Chávez en 2004.

La segunda opción fue la enmienda constitucional. En febrero la AN, de mayoría opositora, recibió un proyecto de enmienda constitucional para reducir el mandato presidencial de seis a cuatro años y prohibir la reelección inmediata. Según la Constitución, la enmienda podía ser solicitada por un $15 \%$ de los inscriptos en el padrón o el $30 \%$ de los integrantes de la AN (51 diputados). Para su aprobación debía someterse a varias discusiones, por lo que podría tardar hasta dos meses.

Asimismo, la Constitución confería a los venezolanos la facultad de convocar a una Asamblea Constituyente con objeto de transformar el Estado, crear un nuevo orden jurídico y redactar otra Ley Fundamental. Esta podía ser activada por las dos terceras partes de la AN o el $15 \%$ de los inscriptos en el registro electoral.

En último lugar, aparecía la renuncia, la opción menos viable, ya que requería la manifestación voluntaria de Maduro, quien remarcó que no renunciaría. Pese a ello, el partido del opositor Leopoldo López, Voluntad Popular, aseguró que era la vía más expedita para sacarlo del cargo y abogaba por la presión popular para impulsar la renuncia.

Como se señaló desde un comienzo en este artículo, la particular relevancia e interés analítico del caso Maduro es que puso en auge varias de las opciones de salida anticipadas del Presidente reconocidas por la Constitución Nacional que, curiosamente, había sido impulsada en 1999 por el propio líder de la revolución bolivariana: el presidente Chávez. Acorde con la teoría de las caídas presidenciales aquí referida, en las últimas décadas, las situaciones de graves crisis generales que acecharon a los países latinoamericanos, ya no fueron resueltas con el desprestigiado recurso de los golpes de Estado o las interrupciones constitucionales sino que, por el contrario, como evidencia la Venezuela de 2016 y 2017, se intentó hacer uso de las válvulas de escape institucionales que la propia Ley Fundamental ofrecía para preservar su continuidad y vigencia. Aunque, como el mismo caso lo demuestra, algunas veces con poco éxito.

La ofensiva nacional corrió en paralelo con la internacional. La AN reclamó a Luis Almagro, secretario general de la Organización de los 
Estados Americanos (OEA), que aplicase la Carta Democrática Interamericana contra el gobierno venezolano ante la alteración del orden constitucional. Almagro podía convocar al Consejo Permanente de la OEA, invocando el artículo $20^{\circ}$ de la Convención, para valorar los ataques al orden democrático de un país miembro. Si esta iniciativa fracasaba, la Asamblea General podía iniciar nuevas gestiones en busca de la normalización de la institucionalidad.

Finalmente, tras plantearse las diferentes opciones, todas las facciones opositoras se alinearon en pos del referendo revocatorio. El 26 de abril, tras dos meses de dilaciones, el CNE, acusado por la oposición de servir al Gobierno, entregó las planillas para la primera recolección de firmas, en el momento en que la imagen del primer mandatario había caído al 15\% a nivel nacional en las encuestas. La oposición debió cambiar para el día siguiente las manifestaciones previstas por un "megafirmazo" en los mismos puntos.

De esta manera se activó el proceso del referéndum, en medio de la alarmante crisis energética que había conducido a Venezuela a un desastre, sometiendo a la población incluso a un plan de racionamiento de electricidad con cortes de luz diarios de cuatro horas, y donde los empleados públicos solo trabajarían los lunes y martes.

El 2 de mayo de 2016 el CNE recibió 1,85 millones de firmas presentadas por la oposición ${ }^{42}$ para cumplimentar el primer paso de promoción de la solicitud de referendo revocatorio, previsto en la Resolución de septiembre de 2007 (por ese entonces aún vigente a pesar de la aprobación de la Ley Orgánica de Referendos en abril de 2016). Si bien solo tenía que entregar 195.721 firmas (1\% del padrón electoral) la MUD recolectó 2,5 millones de adhesiones, y lo hizo en un tiempo mucho menor a los 30 días concedidos a tal fin por la normativa. Ello fue posible gracias al carácter masivo y organizado de la oposición a cargo de motorizar el procedimiento $^{43}$.

En adelante se llevaría a cabo la revisión de firmas frente a testigos del gobierno y la oposición. Luego los firmantes serían llamados a ratificar su aval con la impresión de su huella digital. El CNE debía validar esas primeras firmas para poder autorizar la recolección, en un exiguo plazo de 3 días, de otras casi 4 millones de rúbricas $(20 \%$ del registro electoral) requeridas para la iniciativa popular de convocatoria al referendo.

42 Periódico LA TARDE (2016).

43 Lozano, Daniel (2016c) "La oposición pone en marcha el revocatorio a Maduro". La Nación, 3 de mayo, Buenos Aires [fecha de visita: 7 de mayo de 2016].

[Disponible en: http://www.lanacion.com.ar/1894836-la-oposicion-pone-en-marcha-elrevocatorio-a-maduro]. 
Cabe destacar que lo exiguo del tiempo otorgado por la ley para la junta de avales no hacía más que proteger la continuidad del gobernante en cuestión, atentando contra la efectividad del control popular.

Se iniciaba entonces un "reto contra reloj". La oposición disponía de ocho meses para: conseguir y validar las firmas de la iniciativa popular, lograr que se convocase al referendo revocatorio antes del 10 de enero de 2017 (siendo que Chávez debía haber asumido su nuevo mandato el 10 de enero de 2013), conseguir al menos un voto más que los 7.587.579 alcanzados por Maduro en su elección de 2013, y alcanzar finalmente un llamado a elecciones para su reemplazo.

En virtud de la normativa, si el Presidente era revocado cuando le restaren menos de dos años de mandato, no habría elecciones sino que el vicepresidente (designado en Venezuela por el Presidente y no por elección popular) completaría el período. Por tanto, si el chavismo lograba retrasar el proceso (a través del conocido influjo sobre los órganos de justicia y electorales, por ejemplo, con dilaciones en la revisión de firmas; o por motivo de la reducción de la semana laboral de los empleados públicos ante la crisis energética); el vicepresidente oficialista, Aristóbulo Istúriz, mano derecha de Maduro y designado por este, debería culminar el mandato ${ }^{44}$.

De este modo, se acotaba en gran medida el poder de control popular de este mecanismo de accountability societal, ya que si bien el pueblo tenía la potestad de decidir con su voto la destitución del Presidente, cumplido el cuarto año de mandato, no podía en cambio evitar la continuidad de su línea de gobierno o detener su influencia directa sobre el accionar de su vicepresidente.

Eso fue ciertamente lo ocurrido. Tibisay Lucena, rectora principal del CNE, de orientación chavista, aseguró que la recolección del $20 \%$ de las firmas no se realizaría hasta finales de octubre. Un retraso "injustificado y a la fuerza", que la oposición acusó de incumplir la normativa (según cuyos plazos caería en la primera quincena de septiembre), y que completaba la estrategia "revolucionaria" para mantenerse en el poder. Según el rector independiente, Luis Emilio Rondón, ausente durante el anuncio a modo de protesta, se pudo haber fijado una fecha anterior si la preparación de las máquinas se hubiera realizado en la segunda quincena de agosto, como había propuesto, y no en septiembre. Además denunció que la primera verificación del 1\% debía haber tomado 5 días pero tardó 30 .

44 PARdo, Daniel (2016) "Los 3 grandes obstáculos que enfrenta la oposición de Venezuela para revocar a Maduro". BBC Mundo, 3 de mayo [fecha de visita: 7 de mayo de 2016]. [Disponible en: http://www.bbc.com/mundo/noticias/2016/05/160503_venezuela_referendo_revocatorio_maduro_dp]. 
La sucesión de retrasos sumó casi 70 días para que cuadrasen casi todas las cuentas. Una vez entregadas las firmas, habría que sumar "28 ó 29 días más" para validarlas como paso previo para elegir el día clave del referéndum, "que se llevaría a cabo dentro de los 90 días continuos" ${ }^{55}$. Si bien Lucena no lo dijo abiertamente, todo indicaba que, llegado el caso, consumirían los tres meses marcados, hasta febrero o marzo de 2017. Solo quedaría una pequeña rendija de casi imposible acceso que el chavismo no estaría dispuesto a que sea usada: que el referéndum se celebrase en un solo mes, diciembre. Cabe recordar que el revocatorio de 2004 se prolongó dos meses y las presidenciales exprés tras la muerte de Chávez en 2013 se realizaron en un tiempo récord de 37 días ${ }^{46}$.

Otra estrategia del mayoritariamente oficialista CNE para impedir la celebración del referendo en 2016 era la de usar para la recolección de octubre solo 5.392 máquinas captahuellas de las 40.000 que tenía en su haber, contra las 19.500 pedidas por la oposición. A ello se agregaba una "distribución injusta de las máquinas", pues se dispondrían pocas en los principales centros de votación de las ciudades más grandes y muchas en zonas de difícil acceso o controladas por colectivos (algunos armados) que apoyaban al Gobierno. Finalmente, planeaba exigir el 20\% de firmas por Estado, algo que no estaba establecido en la Constitución ni en la reglamentación, ya que la circunscripción presidencial era nacional ${ }^{47}$. La facultad del CNE de definir la cantidad y ubicación de los puntos de captación de avales estaría aquí dificultando la recolección, en una maniobra protectora del mandatario en cuestión.

A modo de presión para la celebración del referendo, la MUD convocó a la "Toma de Caracas", una multitudinaria protesta realizada el 1 de septiembre en la capital. El 30 de agosto, y nuevamente el 10 de septiembre, el ex Presidente del Gobierno español José Luis Rodríguez Zapatero se reunió con Maduro en nombre de una comisión internacional creada para impulsar el diálogo pacificador en el país. A pesar de contar con algunos apoyos, estas visitas fueron criticadas por Capriles y desconfiadas por otros opositores que no creían en un diálogo promovido por

45 Reuters, Marco Bello (2016) "El chavismo retrasa el revocatorio a 2017 para salvarse". El Mundo, 9 de agosto [fecha de visita: 12 de septiembre de 2016].

[Disponible en: http://www.elmundo.es/internacional/2016/08/09/57aa31ffe2704e9510 8b4570.html].

46 Reuters (2016).

47 Vásquez, Álex (2016) "El Consejo Nacional Electoral ultima la estrategia para el revocatorio". El Mundo, 20 de septiembre, España [fecha de visita: 22 de septiembre de 2016]. [Disponible en: http://www.elmundo.es/internacional/2016/09/20/57e036f3468aeb5971 8b4632.html]. 
el Gobierno, aun cuando estuviese auspiciado por la Unión de Naciones Suramericanas ${ }^{48}$.

El 18 de octubre, a una semana de la fecha prevista para el comienzo de la triple jornada de recolección (del 26 al 28) de las casi 4 millones de firmas necesarias para la convocatoria al referéndum, el TSJ, bajo clara influencia chavista, volvió a sentenciar contra la MUD, al ratificar la resolución del CNE respecto de que la recolección del 20\% de adhesiones se haría por estado y no tomando al país como distrito único (como sostiene la Constitución). La nueva embestida revolucionaria se producía tras la reunión mantenida el sábado anterior entre Maduro y Rodríguez Zapatero en busca del diálogo nacional. Al mismo tiempo, el chavismo convocó a una marcha de sus seguidores en las puertas de la Asamblea Nacional, una especie de "asedio militar" o intimidación.

Esta sentencia era la número 33 de las emitidas por el TSJ en el lapso de 10 meses contra el Parlamento y la oposición: nuevamente la judicialización de la política era la efectiva estrategia de una justicia politizada en defensa de la continuidad del presidente. La falta de recolección de ese porcentaje en cualquiera de los estados o del Distrito Capital haría nugatoria la válida convocatoria del referendo revocatorio presidencial: "El TSJ es el sastre que ajusta el traje constitucional a deseos del Presidente", recriminó el ex rector electoral Vicente Díaz ${ }^{49}$.

La estocada política final llegaría el 20 de octubre cuando el CNE decidió paralizar el proceso revocatorio (previsiblemente para siempre) en obediencia a las órdenes emanadas por jueces de varios estados. A menos de una semana de la fecha asignada, el organismo suspendió la segunda recolección de firmas (ahora del 20\% del padrón) hasta nueva instrucción judicial. La decisión se justificó en virtud de las medidas cautelares dictadas por diferentes jueces de primera instancia (de Apure, Aragua, Bolívar y Carabobo) que admitieron a trámite las querellas criminales presentadas por el oficialismo contra la primera recolección de firmas efectuada en el mes de abril. El oficialismo había denunciado entonces un fraude masivo cuando la oposición dijo tener las firmas del $1 \%$ del electorado para solicitar el revocatorio, el paso inicial exigido por la resolución reglamentaria

48 EFE (2016) "Zapatero prosigue con su labor de mediación y se reúne con Maduro". El Mundo, 11 de septiembre, Espańa [fecha de visita: 12 de septiembre de 2016].

[Disponible en: http://www.elmundo.es/internacional/2016/09/11/57d4a650468aeb3654 8b4620.html].

49 Lozano, Daniel (2016a) "El chavismo dificulta aún más el revocatorio de Maduro y asedia la Asamblea”. El Mundo, 18 de octubre, Espańa [fecha de visita: 9 de septiembre de 2006].

[Disponible en: http://www.elmundo.es/internacional/2016/10/18/5806761d468aeb2a448 b458c.html]. 
a las agrupaciones civiles u organizaciones políticas que se constituyeran en promotoras de una solicitud de revocatoria ${ }^{50}$.

Cabe detenerse en pos de ciertas conclusiones teóricas y empíricas que suscita la creación y uso de los mecanismos de participación y control ciudadano como la revocatoria de mandato. En primer lugar, ocurre que los mismos parten de una situación inicial paradójica: los propios gobernantes a ser controlados son quienes tienen a su cargo el diseño y la reglamentación de los instrumentos de control popular. Con lo cual si bien en un principio estos pueden ser incorporados por líderes políticos y legisladores en las constituciones y principales leyes de la Nación con el fin de transparentar la gestión y de obtener un voto de confianza y credibilidad en la población, muy probablemente la reglamentación de estas herramientas (a cargo de los propios representantes) tenderá a oponer obstáculos al efectivo ejercicio de la accountability vertical, en resguardo de la continuidad de los gobernantes.

Del mismo modo, y por la misma razón, es esperable que la aplicación de estos instrumentos de control como la revocatoria de mandato, responda más a la iniciativa política que a la activación ciudadana, utilizándose con mayor frecuencia al servicio de los intereses particulares del gobierno o de la oposición que al del interés general de la población. Finalmente, es igualmente probable que el gobernante sometido a revocatoria tienda a intervenir en el proceso, ya sea para favorecerlo o para entorpecerlo según sea su conveniencia. Esta intervención es claramente más factible y determinante en el caso de la revocatoria presidencial, debido a los amplios recursos con los que cuenta un Presidente para impulsar o entorpecer un procedimiento iniciado sobre su persona.

En todas estas situaciones, como ocurrió en el caso Maduro aquí analizado, se atenúa el carácter directo del mecanismo debido a la intermediación de intereses político-partidarios. Por tanto, más allá de las elocuentes declamaciones políticas a favor de la participación cívica que suelen ser comunes en tiempos de crisis, a la hora de hacer uso de los mecanismos de democracia directa numerosas son las trabas que aún restan por superar para que puedan aspirar a arrojar resultados concretos y tangibles ya que los propios gobernantes a ser controlados son los que conservan el poder para viabilizar o interrumpir estos procesos.

Suspendido el revocatorio, se apostaría a la vía diplomática, con intervención de importantes figuras de la política mundial, incluyendo

50 Redacción BBC Mundo (2016) "Venezuela: el CNE paraliza el referendo revocatorio a Nicolás Maduro", 21 de octubre [fecha de visita: 10 de diciembre de 2016].

[Disponible en: http://www.bbc.com/mundo/noticias-america-latina-37723172]. 
a representantes del Vaticano. No obstante, ante el fracaso de la vía diplomática y el recrudecimiento del conflicto interno, el Presidente de la Comisión de Política Exterior de la AN, anunció el 10 de diciembre que se retomaría en el Parlamento el juicio por la responsabilidad política de Maduro en la crisis venezolana, así como la causa para determinar el abandono del cargo del Presidente de la República. Ello, debido a que el Ejecutivo no había cumplido con lo acordado en la mesa de diálogo ${ }^{51}$.

Este procedimiento, calificado de juicio político (aunque no se encuentra estipulado de este modo en la Constitución) y penal, había sido iniciado por la AN el 25 de octubre para determinar la responsabilidad del Presidente en la "ruptura del hilo constitucional" por la suspensión del referendo revocatorio. El órgano legislativo había ordenado a una comisión preparar un estudio "sobre la responsabilidad" penal y política y "abandono del cargo", una figura prevista en la Ley Fundamental para cuando el Presidente deja de ejercer sus atribuciones. No obstante, el 1 de noviembre la misma AN opositora suspendió el llamado juicio político ante la posibilidad de dialogar con el régimen para solucionar la crisis nacional, y el 15 de noviembre el bolivariano TSJ declaró inconstitucional, nulo e inexistente dicho procedimiento, anotando la sentencia número 38 contra el legislativo nacional y contra la oposición ${ }^{52}$.

En síntesis, la "jugada tramposa” para mantener al chavismo en el poder, estirar la presidencia de Maduro y desmoralizar a gran parte del país, siguió su curso con éxito. Según las encuestas, si el referéndum se hubiese celebrado en 2016, una cantidad por demás suficiente de entre 11 y 13 millones de venezolanos (68\% de los electores) hubieran votado por revocarlo, contra 2 millones que lo hubieran respaldado. Tras su caí$\mathrm{da}$, las elecciones inmediatas hubieran confirmado el cambio de poder. Por el contrario, de hacerse la consulta en 2017, como sugirió el CNE, y de ser revocado su mandato, le sucedería su vice (designado por este) hasta $2019^{53}$.

En sus múltiples vaivenes y matices, el caso muestra una clara manipulación de las reglas y procedimientos por parte de la autoridad de aplicación (el CNE) y la justicia (el TSJ), controladas ambas por el primer

51 EL NACIONAL Weв (2016) “El juicio político a Maduro continuará la semana que viene”, 10 de diciembre, Caracas [fecha de visita: 10 de diciembre de 2016].

[Disponible en: http://www.el-nacional.com/politica/juicio-politico-Maduro-continuarasemana_0_973702651.html].

52 Lozano, Daniel (2016b) "La justicia venezolana prohíbe el juicio político a Nicolás Maduro". El Mundo, 15 de noviembre, Madrid [fecha de visita: 10 de diciembre de 2016]. [Disponible en: http://www.elmundo.es/internacional/2016/11/15/582b4c0d22601d2d3c8b4 5a7.html].

53 Reuters (2016). 
mandatario en cuestión, que impidió al mecanismo revocatorio desplegar todo su potencial como herramienta de control popular sobre los representantes y como válvula de escape institucional a graves crisis de legitimidad política.

Venezuela comenzó el año 2017 con renovación de autoridades. En la AN se designó como nuevo Presidente a Julio Borges, del partido centrista Primero Justicia (PJ) y jefe de la bancada de la MUD. PJ era el mismo partido del gobernador de Miranda y ex candidato presidencial, Henrique Capriles. Otro cambio de singular importancia fue el nuevo vicepresidente, Tareck El Aissami, quien ocupó numerosos e importantes cargos en la administración chavista. Fue diputado por el Estado de Mérida, viceministro de Prevención y Seguridad Ciudadana, Ministro de Relaciones Interiores y Justicia, vicepresidente del Partido Socialista Unido Venezolano (PSUV) para la región los Andes y luego para la región Centro Occidental y, antes de ocupar la vicepresidencia, fue Gobernador de Aragua. El Aissami era un hombre de confianza de Chávez y se lo reconocía como un "duro" que pertenecía al ala radical del chavismo. Sus detractores especulaban que tenía vinculaciones con el tráfico de drogas y con el Hezbollah. Más allá de la verdad o falsedad de los cargos, era claro que el Presidente Maduro había dado un mensaje claro respecto de la orientación que tendría el chavismo, en caso de que él fuera destituido o removido de su cargo.

Con el correr de los meses se incrementó la situación de emergencia económica, social y alimentaria, y el conflicto entre poderes se agravó. Las sentencias 155 (27 de marzo) y 156 (29 de marzo) del chavista TSJ avivaron la confrontación institucional entre los poderes: redujeron la inmunidad parlamentaria, ordenaron al Presidente la activación del estado de excepción y la adopción de las medidas necesarias (civiles, económicas, militares, penales, administrativas, políticas, jurídicas y sociales) para salvaguardar el orden constitucional, y quitaron a la Asamblea Nacional sus competencias por "desacato" de las sentencias de ese órgano judicial, traspasándolas a la Sala Constitucional del propio tribunal ${ }^{54}$.

Estas medidas recibieron una desaprobación mundial y se tildó a lo ocurrido como un golpe de Estado o como la disolución del Parlamento. En el mundo diplomático, con mayor cautela, se señaló el grave retroceso que estaba sufriendo la democracia venezolana ${ }^{55}$. La fuerte oposición

54 LA IGUANA.TV (2017) “Acá están las sentencias 155 y 156 dictadas por el TSJ que generaron la controversia", La Iguana.TV, 1 de abril [fecha de visita: 10 de julio de 2017]. [Disponible en: http://www.laiguana.tv/articulos/52733-sentencias-155-156-tsj].

55 Serrafero, Mario Daniel (2017) “Venezuela, ¿̇democracia o autoritarismo?”, El Estadista, 28 de abril, Buenos Aires [fecha de visita: 3 de julio de 2017].

[Disponible en: http://elestadista.com.ar/?p=12557]. 
interna e internacional redundó en un pedido lanzado por Maduro para que se revisaran dichas sentencias, a las que se dio marcha atrás: se suprimieron los superpoderes del Presidente y se restableció la inmunidad a los parlamentarios.

En las semanas siguientes se multiplicaron las protestas callejeras, arrojando decenas de muertos. Si bien el Presidente prometió elecciones regionales para fines de 2017, mantuvo su enérgica confrontación con la oposición, restando verosimilitud a toda esperanza de diálogo o acuerdo. La situación se volvió aún más intensa y violenta, poniendo en duda la calidad democrática del régimen.

En síntesis, en Venezuela, institucionalmente, hay hoy un enfrentamiento total de las ramas de gobierno electivas, la judicialización de la política se ha llevado a un grado tal que el Poder Judicial es un apéndice absoluto del chavismo, la experiencia de populismo radical del régimen está en fase de colapso y la polémica se cierne acerca de si el experimento chavista sigue siendo una democracia o ha ingresado definitivamente al territorio de las dictaduras o los autoritarismos ${ }^{56}$.

(...) Con el chavismo se convirtió en una democracia populista que, de por sí, dista del modelo de democracia liberal republicana. La pregunta es, en todo caso, cuándo se traspasa el umbral de la democracia (incluso en su versión populista) y se ingresa en el territorio del autoritarismo. La respuesta es: cuando las elecciones limpias, trasparentes y competitivas dejan de ser el requisito y el fundamento de legitimidad de los gobernantes. El gobierno chavista clausuró en la práctica y arbitrariamente el proceso de referéndum revocatorio promovido por la oposición. Poco después suspendió las elecciones regionales. A través de estos actos comenzó, al menos, un claro desplazamiento o transición de régimen ${ }^{57}$.

Recientemente, el Presidente decidió poner en marcha un proceso constituyente, según él, como único camino para pacificar el país. La oposición rechazó la iniciativa gubernamental y la AN convocó su propia consulta popular para expedirse sobre este proceso, amparada en el artículo $350^{\circ}$ de la Constitución que dice que: "El pueblo de Venezuela, fiel a su tradición republicana, a su lucha por la independencia, la paz y la libertad, desconocerá cualquier régimen, legislación o autoridad que contraríe los valores, principios y garantías democráticos o menoscabe los

\footnotetext{
56 Serrafero (2017).

57 Serrafero (2017).
} 
derechos humanos". El 16 de julio 7,2 millones de venezolanos participaron de la consulta popular opositora, en contra de la constituyente de Maduro.

No obstante, el gobierno organizó en tiempo récord la elección constituyente y la llevó a cabo el 30 de julio. Los comicios y la conformación de la Asamblea Nacional Constituyente fueron acusados de fraude, rechazados y desconocidos por casi toda la comunidad internacional y por la oposición. Con la Constituyente, Venezuela formalmente puso fin a un régimen democrático que hacía tiempo se deslizaba hacia un sistema autoritario. El Mercosur, en reunión de sus cancilleres de Brasil, Argentina, Paraguay y Uruguay en la ciudad de San Pablo, aplicó el Protocolo de Ushuaia (1998) y Venezuela fue suspendida por "ruptura del orden democrático".

\section{4) PERSPECTIVAS A CORTO Y MEDIANO PLAZO}

Cabe hacer una reflexión adicional respecto de los movimientos de Maduro (y el chavismo) en la evolución y desenlace del gobierno (y el régimen). Respecto de la oposición, la salida elegida había sido la revocatoria del mandato que se frustró gracias a la intervención obstaculizadora del propio gobierno. Más tarde, el Presidente derrochó las vías negociadas cuando luego de la suspensión del revocatorio en octubre de 2016, los diálogos de paz fracasaron. Acto seguido Maduro optó por la convocatoria de una Asamblea Constituyente y la reforma de la Constitución.

La posición del oficialismo es clara: ubicarse en el lugar de la institucionalidad, denunciar a la oposición de violenta y golpista y pretender seguir caminos constitucionales, aunque casi nadie crea este guión de la crisis y su modo de supuesta resolución. Sin embargo, el propio chavismo se encuentra en vías a su mayor fisura luego de la convocatoria de la Constituyente. El ala crítica se ha incrementado con la profundización de la crisis.

¿Cuáles serían las vías de resolución? Hay (al menos) dos posibilidades. O el gobierno regresa como primer paso hacia las coordenadas de una mínima democracia electoral o sigue camino hacia un régimen aún más autoritario con un contorno más definido y asumiendo su verdadera naturaleza. La vía electoral presenta distintas variantes. La primera, una salida electoral inmediata que Maduro no desea. La segunda, un acuerdo que permita una transición pacífica hacia unas elecciones a mediano plazo. La tercera, que la oposición desarticule su resistencia y pasivamente espere hasta las elecciones según el calendario ordinario, en 2019. 
Pero la oposición comenzó en el mes de abril una resistencia y una ocupación permanente de las calles. Difícil es volver sobre sus propios pasos con nada en las manos. Asimismo, la alternativa electoral, a esta altura de los acontecimientos, seguramente exigiría por parte del gobierno una suerte de amnistía para evitar el juzgamiento de los hombres y mujeres del régimen por los delitos cometidos durante su gestión y en su fase de endurecimiento. Al presidente Maduro solo le queda el recuerdo de su origen democrático.

La otra alternativa, justamente, es profundizar el tránsito hacia un modelo más autoritario. La Asamblea Constituyente puede ser la instancia para suturar una Venezuela definidamente autoritaria con la fachada de la supuesta construcción de una fase superior de la revolución bolivariana plasmada en un nuevo régimen. Por eso el riesgo es mayor.

\section{CONCLUYENDO: LAS OPCIONES DE LA SALIDA INSTITUCIONAL}

Aunque la dinámica de los hechos, con el reciente establecimiento de una Asamblea Constituyente (viciada de fraude y carente de legitimidad alguna) parecería clausurar los caminos establecidos por la Carta Fundamental al haberse ingresado en un rumbo incierto, repasamos las alternativas referidas en el principio del trabajo.

En primer lugar cabe destacar que de acuerdo con la Constitución venezolana cualquier interrupción presidencial pasado el cuarto año del período del mandato implica que no habrá convocatoria a elecciones, sino la sucesión de un vicepresidente que no es elegido por la población, sino que es designado por el propio presidente. Esto significa que, en el caso concreto aquí analizado, el control de la situación institucional estaría en manos del chavismo y en la figura del vicepresidente.

Luego de este recorrido las salidas constitucionales parecen dificultosas. No es esperable la renuncia de Maduro pues así lo ha manifestado reiteradamente, además de contar con las fuerzas armadas y el Estado. Aunque, no cabe descartar que una renuncia no sería tan costosa en 2017 pues el chavismo, como se dijo, continuaría gobernando hasta el fin del mandato con la figura dura de El Aissami. No obstante, la renuncia del mandatario podría iniciar un camino de transición hacia el restablecimiento del régimen democrático.

En relación con la causal de destitución por el TSJ, su alineación absoluta con el chavismo lo torna prácticamente imposible. Respecto de la causal de abandono del cargo del Presidente, sería lisa y llanamente una suerte de censura o destitución del mandatario por la Asamblea Nacional, 
sin fundamento fáctico pues está claro que Maduro no ha abandonado el cargo. Un cuestionable desempeño de la presidencia no es lo mismo que su abandono. La causal de inhabilidad física o mental del Presidente no se ha planteado. Debería contar con la intervención de la Asamblea Nacional y del TSJ. El juicio político que intentó llevar adelante por la Asamblea Nacional no existe en la Constitución venezolana. Así lo ha hecho saber el propio TSJ.

En definitiva, hay dos cuestiones relevantes a considerar. En primer lugar, el diseño institucional, que de alguna manera configura un blindaje que protege al Presidente si este cuenta con un Poder Judicial dependiente o a su favor, o bien controla la Asamblea Nacional. En segundo lugar, en el caso de Venezuela, luego de las elecciones legislativas de 2015 la Asamblea Nacional pasó a manos opositoras. Se dio así una ecuación de dos poderes contra uno: el Ejecutivo y el Judicial en manos del chavismo, y el Legislativo controlado por la oposición. A partir de allí, el papel del TSJ fue clave para limitar las facultades del Legislativo y torcer la balanza para la continuidad del gobierno de Maduro.

Nótese que la destitución es un procedimiento en cabeza del TSJ, la intervención de la Asamblea Nacional se limita a su autorización luego de que dicho tribunal declara el mérito para su juzgamiento. Ello se diferencia de varios países de la región que tienen el procedimiento de impeachment con resolución en el ámbito del Legislativo. En la Constitución venezolana las medidas para concluir con un gobierno requieren generalmente la intervención de los poderes Legislativo y Judicial (salvo la causal de abandono) con lo cual, controlando uno de ellos, se produce un verdadero veto a la acción en contra del mandatario.

Es cierto que existen caminos que podrían transitarse a través de la acción y participación de la población, como la revocatoria de mandato, pero se ha visto que, aquí también, los poderes constituidos pueden obstaculizar la voluntad popular. El modo en que se bloqueó el proceso revocatorio es un claro ejemplo. Fue el Poder Judicial el que llegó a suspender un referendo que, seguramente, de haberse efectivizado en 2016, hubiera concluido con el mandato de Maduro.

La vía diplomática, como se señaló, fue una buena iniciativa para evitar la explosión del sistema político venezolano. Pero las dos partes del conflicto ya tenían posiciones tomadas, sin intenciones de modificarlas. Maduro había seńalado que no permitiría que la oposición ocupara la presidencia y los opositores no veían ninguna salida que no fuera a través de elecciones. La vía diplomática, dialoguista y negociada podría ser, en todo caso, un camino para allanar la transición. 
Especial consideración ha tenido en este trabajo el intento de poner fin al mandato del Presidente a través de la revocatoria del mandato. Venezuela es uno de los tres países de América Latina que tienen este dispositivo de democracia directa para destituir a un presidente. No obstante, se vio la cantidad de obstáculos y dificultades que el poder oficialista fue estableciendo con el objetivo de minar el referéndum revocatorio.

En este artículo se han recorrido los caminos que prescribe el texto constitucional para superar crisis políticas de gravedad. Al momento de escribir este trabajo no se ha solucionado constitucionalmente la crisis venezolana, en realidad, se ha agravado con la convocatoria y el establecimiento de una ilegítima Asamblea Constituyente. Cabe aclarar que, aunque no sea materia de este trabajo, las opciones posibles exceden las aquí tratadas. Otros caminos más oscuros y alejados de la Constitución podrían ser la toma violenta del poder (de opositores o disidentes dentro del propio chavismo), o la consolidación del régimen chavista en una dictadura aún más represiva.

Por lo demás, en términos generales observamos que la reforma constitucional llevada a cabo por Hugo Chávez en 1999 si bien presumió de su carácter participativo y dotó a la ley fundamental de numerosas y novedosas herramientas para la participación directa de la ciudadanía, al mismo tiempo sujetó su implementación a la anuencia del Ejecutivo, restando real poder de control a la ciudadanía. Las numerosas dilaciones e interferencias que el Consejo Nacional Electoral y el TSJ llevaron a cabo contra el normal desempeño de la revocatoria de mandato, llegando incluso a la interrupción total del proceso, dan cuenta de la debilidad de estas instituciones cuando dependen en su aplicación de la voluntad política de quienes detentan el poder. Más aún cuando, como en este caso, el blanco de la misma es el propio Presidente.

\section{BIBLIOGRAFÍA CITADA}

Acevedo, Génesis (2016) "7 salidas para salir de la crisis explicadas por un constitucionalista". El tubazo digital, 2 de marzo, [fecha de visita: 28 de diciembre de 2016].

[Disponible en: http://www.eltubazodigital.com/noticias-devenezuela/7-salidas-para-salir-de-la-crisis-explicadas-por-unconstitucionalista/]

Aragón Reyes, Manuel y López González, José Luis (2000) "Plebiscito". En Diccionario electoral (Tomo II). San José: Instituto Interamericano de Derechos Humanos, pp. 981. 
Bejarano, Ana María (2005) "Transformaciones de la democracia en Venezuela: una lectura crítica de la constitución de 1999”, Desafíos, vol. 12, enero-junio.

Biscaretti di Ruffia, Paolo (2000) Introducción al Derecho Constitucional Comparado, México: Fondo de Cultura Económica.

Brewer-Carías, Allan (2007) "El inicio del proceso constituyente en Ecuador en 2007 y las lecciones de la experiencia venezolana de 1999", Iuris dictio Año 12. Vol 14.

Briceno Pérez, Irving (2016) "Enmienda constitucional produce cambio de régimen pero puede extenderse hasta 2019”. Efecto Cocuyo, 6 de diciembre [fecha de visita: 28 de diciembre de 2016].

[Disponible en: http://efectococuyo.com/politica/la-enmiendaconstitucional-cambia-el-regimen-pero-puede-extendersehasta-2019]

Carey, John (2006) "Presidencialismo versus parlamentarismo". PostData, $\mathrm{N}^{\circ} 11$, pp. 121-160.

Combellas, Ricardo (2002) "La Constitución de 1999 y la reforma política: implicaciones para la gobernabilidad democrática", VII Congreso Internacional del CLAD sobre la Reforma del Estado y de la Administración Pública, Lisboa, Portugal, 8-11 Oct.

Eberhardt, María Laura (2013) "Crisis de la representación en las democracias presidencialistas latinoamericanas $i \mathrm{La}$ revocatoria de mandato como opción?”. Revista Elecciones, Vol. 12 N 13, pp. 13-51.

Eberhardt, María Laura (2016a) "La Revocatoria de Mandato en Bolivia. Su diseńo institucional. El caso Evo Morales (2008)". Acciones e Investigaciones Sociales, $\mathrm{N}^{\circ} 36$, pp. 253-278.

Eberhardt, María Laura (2016b) "La Revocatoria de Mandato en Venezuela y su diseño institucional: el caso Hugo Chávez (2004)". Revista Brasileira de Sociología, Vol. 04 N $^{\circ} .8$ Jul. Dez; pp. 59-92.

EFE (2016) "Zapatero prosigue con su labor de mediación y se reúne con Maduro". El Mundo, 11 de septiembre, España [fecha de visita: 12 de septiembre de 2016].

[Disponible en: http://www.elmundo.es/internacional/2016/09/11/5 7d4a650468aeb36548b4620.html]

El Deber Mundo (2015) “Oposición venezolana buscará revocatoria de Maduro en 2016”, 10 de noviembre, Santa Cruz de la Sierra [fecha de visita: 4 de marzo de 2006].

[Disponible en: http://www.eldeber.com.bo/mundo/oposicionvenezolana-buscara-revocatoria-maduro.html]

El Nacional Web (2016) "El juicio político a Maduro continuará la semana que viene", 10 de diciembre, Caracas [fecha de visita: 10 de diciembre de 2016]. 
[Disponible en: http://www.el-nacional.com/politica/juicio-politicoMaduro-continuara-semana_0_973702651.html]

Hochstetler, Kathryn y Samuels, David (2011) "Crisis and Rapid Reequilibration. The Consequences of Presidential Challenge and Failure en Latin America". Comparative Politics, 43, 2, pp. 127-145.

KIM, Young Hun y BaHrY, Donna (2008) "Interrupted Presidencies in Third Wave Democracies". The Journal of Politics, 70, 3, pp. 807822.

La Iguana.TV (2017) "Acá están las sentencias 155 y 156 dictadas por el TSJ que generaron la controversia", La Iguana.TV, 1 de abril [fecha de visita: 10 de julio de 2017].

[Disponible en: http://www.laiguana.tv/articulos/52733-sentencias155-156-tsi].

La Patilla (2016) "La revocatoria del mandato en Venezuela: un procedimiento innecesariamente complejo", 17 de marzo [fecha de visita: 24 de abril de 2016].

[Disponible en: http://www.lapatilla.com/site/2016/03/17/ la-revocatoria-del-mandato-en-venezuela-un-procedimientoinnecesariamente-complejo]

LinZ, Juan José (1988) "Democracia presidencialista o parlamentarista. ¿Hay alguna diferencia?”. Presidencialismo vs. Parlamentarismo. Materiales para el estudio de la Reforma Constitucional en la Argentina. Buenos Aires: Eudeba, 168 pp.

Linz, Juan José (1990) "Democracia: Presidencialismo o Parlamentarismo ¿Hace alguna diferencia?”. En Godoy Arcaya, Oscar (editor) Hacia una democracia moderna. La opción parlamentaria. Santiago: Editorial Universidad Católica de Chile, pp. 41-108.

Linz, Juan José (1987) La quiebra de las democracias. Madrid: Alianza, $169 \mathrm{pp}$.

Linz, Juan José (1994) "Presidential or Parliamentary Democracy: Does It Make a Difference?. En Linz, Juan José y Valenzuela, Arturo The Failure of Presidential Democracy, Vol. 1, The Johns Hopkins University Press, pp. 3-87.

Llanos, Mariana (2010) "Presidential Breakdown in Argentina". En Presidential Breakdowns in Latin America. Palgrave: Macmillan, pp. 55-71.

Lozano, Daniel (2016a) "El chavismo dificulta aún más el revocatorio de Maduro y asedia la Asamblea". El Mundo, 18 de octubre, Espańa [fecha de visita: 9 de septiembre de 2006].

[Disponible en: http://www.elmundo.es/internacional/2016/10/18/5 806761d468aeb2a448b458c.html]

Lozano, Daniel (2016b) "La justicia venezolana prohíbe el juicio político a Nicolás Maduro". El Mundo, 15 de noviembre, Madrid [fecha de visita: 10 de diciembre de 2016]. 
[Disponible en: http://www.elmundo.es/internacional/2016/11/15/5 82b4c0d22601d2d3c8b45a7.html]

Lozano, Daniel (2016c) "La oposición pone en marcha el revocatorio a Maduro". La Nación, 3 de mayo, Buenos Aires [fecha de visita: 7 de mayo de 2016].

[Disponible en: http://www.lanacion.com.ar/1894836-la-oposicionpone-en-marcha-el-revocatorio-a-maduro]

LynN KarL, Terry (1988) "El petróleo y los pactos políticos: La transición a la democracia en Venezuela”. En O’Donnell, Guillermo; Schmitter, Philippe y Whitehead, Lauraence Transiciones desde un gobierno autoritario, Tomo 2. Buenos Aires: Paidós, 359 pp.

Marsteintredet, Leiv (2013) "Explaining variation of executive instability in presidential regimes: Presidential interruptions in Latin America”. En International Political Science Review, 7 January, pp. 173-194.

Marsteintredet, Leiv (2008) “Las consecuencias sobre el régimen de las interrupciones presidenciales en América Latina”. América Latina Hoy, Vol. 49, pp. 31-50.

Marsteintredet, Leiv y Berntzen, Einar (2008) "Reducing the Perils of Presidentialism in Latin America through Presidential Interruptions". Comparative Politics, Vol. $41 \mathrm{~N}^{\circ} 1$, pp. 83-101.

Marsteintredet, Leiv; Llanos, Mariana y Nolte, Detlef (2013) "Paraguay and the Politics of Impeachment". Journal of Democracy, 24 4, pp.110-123.

Mejía Acosta, Andrés y Polga-Hecimovich, John (2011a) "Coalition Erosion and Presidential Instability in Ecuador". Latin American Politics and Society, 53 2, pp. 87-111.

Mejía Acosta, Andrés y Polga-Hecimovich, John (2011b) "Soluciones Parlamentarias a las crisis presidenciales de Ecuador". Revista Latinoamericana de Política Comparada, Vol. 4, pp. 49-73.

Njaim, Humberto (2005) "La gobernabilidad en Venezuela: un desastre previsible". En Valadés, Diego Gobernabilidad y constitucionalismo en América Latina, México: Universidad Nacional Autónoma de México, pp. 253-274

Negretto, Gabriel (2006) "Minority Presidents and Types of Government in Latin America”. Latin American Politics and Society, 483 , pp. 63-92.

Llanos, Mariana y Nolte, Detlef (2006) Los Congresos en América Latina: Legislaturas reactivas, potencialmente activas. México: Cámara de Diputados, pp. 29-54.

PArdo, Daniel (2016) "Los 3 grandes obstáculos que enfrenta la oposición de Venezuela para revocar a Maduro". BBC Mundo, 3 de mayo [fecha de visita: 7 de mayo de 2016]. 
[Disponible en: http://www.bbc.com/mundo/ noticias/2016/05/160503_venezuela_referendo_revocatorio_ maduro_dp]

Pérez-Liñán, Aníbal (2007) Presidential Impeachment and the New Political Instability in Latin América Cambridge. New York: Cambridge University Press, 213 pp.

Periódico La Tarde (2016) "Arrancó revisión de firmas para revocatoria Maduro", 5 de mayo [fecha de visita: 5 de mayo de 2016]. [Disponible en: http://www.latarde.com/actualidad/mundo/169662arranco-revision-de-firmas-para-revocatoria-de-maduro]

Real Academia Española (2016) "Diccionario de la Lengua Española" [fecha de visita: 28 de diciembre de 2016].

[Disponible en: http://dle.rae.es/?id=Vyqz9zm]

Redacción BBC Mundo (2016) "Venezuela: el CNE paraliza el referendo revocatorio a Nicolás Maduro", 21 de octubre [fecha de visita: 10 de diciembre de 2016].

[Disponible en: http://www.bbc.com/mundo/noticias-americalatina-37723172]

Reuters, Marco Bello (2016) "El chavismo retrasa el revocatorio a 2017 para salvarse". El Mundo, 9 de agosto [fecha de visita: 12 de septiembre de 2016].

[Disponible en: http://www.elmundo.es/internacional/2016/08/09/5 7aa31ffe2704e95108b4570.html]

Serrafero, Mario Daniel (2002) "Argentina: Rebelión en el granero del mundo". Revista de Occidente, No 251, pp. 19-51.

Serrafero, Mario Daniel (2014) "Flexibilización del presidencialismo en América Latina: ¿̇un fenómeno nuevo?". Revista de Estudios Politicos, $\mathrm{N}^{\circ}$ 163, pp. 67-99.

Serrafero, Mario Daniel (2016) "La crisis de Venezuela". El Estadista, 18 de noviembre, Buenos Aires [fecha de visita: 9 de diciembre de 2016].

[Disponible en: http://elestadista.com.ar/?p=11703]

Serrafero, Mario Daniel (2017) "Venezuela, ¿democracia o autoritarismo?", El Estadista, 28 de abril, Buenos Aires [fecha de visita: 3 de julio de 2017].

[Disponible en: http://elestadista.com.ar/?p=12557].

Vásquez, Álex (2016) "El Consejo Nacional Electoral ultima la estrategia para el revocatorio". El Mundo, 20 de septiembre, España [fecha de visita: 22 de septiembre de 2016].

[Disponible en: http://www.elmundo.es/internacional/2016/09/20/5 7e036f3468aeb59718b4632.html] 


\section{JuRisprudenCIA CiTADA}

Asamblea Nacional. 30 de diciembre de 1999. "Constitución de la República Bolivariana de Venezuela”. Gaceta Oficial Nº 36.860.

Asamblea Nacional. 20 de febrero de 2009. "Constitución de la República Bolivariana de Venezuela con la enmienda No 1”. Gaceta Oficial Extraordinaria $N^{\circ} 5.908$.

Consejo Nacional Electoral. 18 de diciembre de 2007. Resolución No 070906-2770 "Normas para Regular el Procedimiento de Promoción y Solicitud de Referendos Revocatorios de Mandatos de Cargos de Elección Popular”. Gaceta Electoral Nº 405. 